\title{
Repeated gestational exposure to diesel engine exhaust affects the fetal olfactory system and alters olfactory-based behavior in rabbit offspring
}

Estefanía Bernal-Meléndez ${ }^{1,2}$, Marie-Christine Lacroix¹, Pascaline Bouillaud ${ }^{2}$, Jacques Callebert ${ }^{3}$, Benoit Olivier², Marie-Annick Persuy ${ }^{1}$, Didier Durieux ${ }^{1}$, Delphine Rousseau-Ralliard ${ }^{4}$, Josiane Aioun ${ }^{4}$, Flemming Cassee, ${ }^{5,6}$, Anne Couturier-Tarrade ${ }^{4}$, Sarah Valentino ${ }^{4}$, Pascale Chavatte-Palmer ${ }^{4}$, Henri Schroeder ${ }^{2}$ and Christine Baly ${ }^{1 *}$ (D)

\begin{abstract}
Background: Airborne pollution, especially from diesel exhaust (DE), is known to have a negative effect on the central nervous system in exposed human populations. However, the consequences of gestational exposure to DE on the fetal brain remain poorly explored, with various effects depending on the conditions of exposure, as well as little information on early developmental stages. We investigated the short-term effects of indirect DE exposure throughout gestation on the developing brain using a rabbit model. We analyzed fetal olfactory tissues at the end of gestation and tested behaviors relevant to pups' survival at birth.

Pregnant dams were exposed by nose-only inhalation to either clean air or DE with a content of particles (DEP) adjusted to $1 \mathrm{mg} / \mathrm{m}^{3}$ by diluting engine exhaust, for $2 \mathrm{~h} /$ day, 5 days/week, from gestational day 3 (GD3) to day 27 (GD27). At GD28, fetal olfactory mucosa, olfactory bulbs and whole brains were collected for anatomical and neurochemical measurements. At postnatal day 2 (PND2), pups born from another group of exposed or control female were examined for their odor-guided behavior in response to the presentation of the rabbit mammary pheromone 2-methyl-3-butyn-2-ol (2MB2).

Results: At GD28, nano-sized particles were observed in cilia and cytoplasm of the olfactory sensory neurons in the olfactory mucosa and in the cytoplasm of periglomerular cells in the olfactory bulbs of exposed fetuses. Moreover, cellular and axonal hypertrophies were observed throughout olfactory tissues. Concomitantly, fetal serotoninergic and dopaminergic systems were affected in the olfactory bulbs. Moreover, the neuromodulatory homeostasis was disturbed in a sex-dependent manner in olfactory tissues. At birth, the olfactory sensitivity to 2MB2 was reduced in exposed PND2 pups.

Conclusion: Gestational exposure to DE alters olfactory tissues and affects monoaminergic neurotransmission in fetuses' olfactory bulbs, resulting in an alteration of olfactory-based behaviors at birth. Considering the anatomical and functional continuum between the olfactory system and other brain structures, and due to the importance of monoamine neurotransmission in the plasticity of neural circuits, such alterations could participate to disturbances in higher integrative structures, with possible long-term neurobehavioral consequences.
\end{abstract}

Keywords: Airborne pollution, Diesel exhaust, Nano-particulate matter, Gestational exposure, Olfactory dysfunction, Olfactory toxicity, Bulbar neurotransmitter disturbances, Pheromonal response, Olfactory-based behavior

\footnotetext{
* Correspondence: christine.baly@inra.fr

${ }^{1}$ NeuroBiologie de I'Olfaction, INRA, Université Paris-Saclay, 78350

Jouy-en-Josas, France

Full list of author information is available at the end of the article
}

(c) The Author(s). 2019 Open Access This article is distributed under the terms of the Creative Commons Attribution 4.0 International License (http://creativecommons.org/licenses/by/4.0/), which permits unrestricted use, distribution, and reproduction in any medium, provided you give appropriate credit to the original author(s) and the source, provide a link to the Creative Commons license, and indicate if changes were made. The Creative Commons Public Domain Dedication waiver (http://creativecommons.org/publicdomain/zero/1.0/) applies to the data made available in this article, unless otherwise stated. 


\section{Background}

Air pollution is a mixture of several components, among which particulate matter (PM) is believed to be the most widespread threat to human health and has been heavily implicated in various human diseases [1-3]. Among these components, diesel exhaust particles (DEP) represent a major source of PM-polluted air in urban environments (reviewed in $[4,5]$ ). Several lines of research have led to the concern that the central nervous system (CNS) represents a relevant target for such particles through chronic inflammation, disruption of the blood-brain barrier and microglia activation, which may contribute to CNS diseases [6-10]. Even though few studies have examined the toxic effects following a controlled exposure to DE in humans $[11,12]$, increasing epidemiological evidence, as well as experimental and in vitro studies, have demonstrated that direct exposure to air pollutants lead to adverse neuropsychological effects such as decreased cognitive function, depressive symptoms, and neurophysiological disturbances, including olfactory dysfunction and auditory deficits [8, 13-17], along with early hallmarks of neurodegenerative diseases such as Alzheimer's disease (AD) and Parkinson's disease (PD) in elders [16-20]. Emerging data indicate that children may be particularly susceptible to air pollution-induced neurotoxicity, given their relatively immature detoxification mechanisms [13, 19, 21-26]. Consequently, gestational exposure to airborne pollution may affect fetal brain development during critical phases and might predispose the individual to neurodevelopmental and neurodegenerative diseases later in life [19].

In the last decade, epidemiological studies have highlighted a possible role of gestational exposure to air pollution in the onset of neurodevelopmental disorders, including autistic spectrum and attention deficit hyperactivity disorders, along with other learning and behavioral disabilities [24-32]. Moreover, experimental studies have shown that gestational exposure to ambient PM induces oxidative stress and inflammation as well as structural and molecular alterations of neurons in brain tissues, that might lead to postnatal neurobehavioral disorders [33-38]. Indeed, DE exposure is related to apoptotic and "swelling" phenomena in offspring neural cells and astrocyte end-feet surrounding brain capillaries, supporting the hypothesis of physiopathological abnormalities and the subsequent neurobehavioral disorders $[37,39,40]$.

Interestingly, imbalances in the monoaminergic systems related to various neurocognitive disorders have also been noticed. Studies performed by Yokota et al. in mice [41-43] pointed out that maternal exposure to DE leads to perturbations of the offspring's dopaminergic, noradrenergic and serotoninergic systems in specific brain regions that could be related to motor coordination and impulsive behavior disturbances. Nevertheless, some incongruence remains as another study has revealed contradictory monoaminergic changes [44], possibly based on different mixtures or routes used for exposure. Moreover, there are still some controversies on their effects during fetal life on cognitive function. Indeed, one study examining mice exposed to DEP in utero showed deficits in the Morris water maze test, but no differences in the passive avoidance learning test [45], whereas other studies reported no effect on learning and memory tasks $[36,46]$. Furthermore, studies have shown that DE, DEP, black carbon, or $\mathrm{NO}_{2}$ exposure during pregnancy in mice could cause motor deficits in offspring and affect central glutamatergic and dopaminergic neurochemistry in a sex-specific manner [41, 44, 45, 47, 48].

Interestingly, olfactory dysfunction, which is a very common feature in numerous neurodegenerative disorders (such as $\mathrm{AD}$ and $\mathrm{PD}$ ) preceding the cognitive and motor symptoms (reviewed by $[49,50]$ ), has been described after direct exposure to air pollution in rodents, dogs and humans $[13,15,51-53]$. The studies conducted to date have shown some hallmarks of AD-like and PD-like neuropathology in human olfactory bulbs (OB), as reflected by neuroinflammation, oxidative stress, DNA damage, and up-regulation of neurodegenerative-disease markers $[15,52]$. Post-mortem studies in humans have identified the accumulation of ultrafine particular matter (UFPM, i.e., particles with mean diameters $<100 \mathrm{~nm}$ ) and inflammatory mediators in olfactory mucosa $(\mathrm{OM})$ and OBs of children and young adults from highly polluted areas of Mexico City [13, 51, 53], suggesting that olfactory pathologies may be considered as a reliable early marker, indicative of disturbances induced in higher integrative brain structures $[49,50,53-55]$. Nevertheless, the mechanisms linking olfactory dysfunction, pollution and the development of neurodegenerative disorders are incompletely understood. Direct effect of nanoparticles in the olfactory system as well as indirect effects or both could be responsible for the observed phenotypes. Indeed, neurodegenerative disorders have been associated with protein aggregate accumulation in the olfactory system $[15,52,56,57]$ and modification of the number of olfactory dopaminergic neurons in the OB [58-60], but have also been linked to alterations in the cholinergic, noradrenergic, and serotoninergic neuromodulatory systems innervating olfactory structures $[49,55,61]$.

Animal research has confirmed and expanded the observed findings in humans, and has shown that the fetal stage is a critical period of vulnerability. Nevertheless, the effects on the CNS of a gestational exposure to air pollution at such a critical period for its anatomic and functional development remain questioned and have been poorly investigated in controlled conditions mimicking indirect human exposure and in early postnatal stages [39-43]. Moreover, how the neuroanatomical continuum between brain and olfactory tissues is impacted by DE exposure remains largely unknown. 
To investigate these aspects, we took advantage of a rabbit model recently developped to analyse the toxicity of repeated in utero DE exposure on the foetoplacental development, and we used a controlled inhalation system delivering a polluted air enriched in NP of small size $(<$ $500 \mathrm{~nm}$ ) and with a low concentration of non-inert gases [62]. The rabbit was used because of its hemodichorial placentation which is anatomically and functionally closer to that in humans than that in rodents [36, 37, 62, 63]. Based on this controlled nose-only inhalation study, previous studies have demonstrated that the feto-placental development is disturbed by maternal exposure to $\mathrm{DE}$, with translocation of nanoparticle-like structures, most probably originating from the diesel exhaust, from the dams to the fetal systemic circulation across placenta [62, 64]. We investigated the olfactory system as a peripheral highly vascularized tissue at the interface between the maternal environment and the brain, as well as an indicator of disturbances in higher integrative brain structures. Our hypothesis was that the maternal inhaled DE could reach the fetal olfactory pathway, either through the hematogenic pathway or through the OM (in contact with the amniotic fluid), then the $\mathrm{OB}$ (throughout nerve bundles), thus resulting in brain penetration of nanoparticles with potential early neurotoxic effects. To better characterize events of predisposition to neurodevelopmental disorders, investigations focused on the early stages of development.

\section{Results}

Transmission Electron microscopy (TEM) analysis Structural and ultrastructural changes in the $O M$

Observations were made at different levels of the OM, from the apical part of the epithelium in contact with the mucus to the axon fascicles under the lamina propria (Fig. 1). OM of control fetuses exhibited a normal general morphology, with a pseudo-stratified columnar organization, a dense submucosal layer with blood vessels (Fig. 1a) and the presence of numerous organized nerve bundle sections (Fig. 1c). Even though exposed fetuses showed an OM of normal thickness, they exhibited relative disorganization of the epithelial cell layer, with several empty spaces visible at the basal level (Fig. 1b, see black arrows). The fasciculation of axons under the lamina propria was also impacted with axon bundle sections appearing usually less compact (Fig. 1d compared to Fig. 1c). The morphological alterations were noticed in all samples of exposed fetuses, but their severity was variable among zones.

At the ultrastructural level, despite comparable cilia density between exposed and control fetuses at the apical part of the OM, altered cell organelle density was observed in the dendritic endings of some exposed fetuses' olfactory sensory neurons (OSN) (Fig. If compared to 1e). Under the lamina propria, hypertrophy of axons in the nerve bundle sections was noticed in all exposed fetuses (Fig. 1d compared to 1c). These alterations were confirmed at higher magnification (Fig. 1h, see white arrows). Chromatin was condensed and marginalized in the olfactory ensheating cells (OEC), as shown by the presence of dense patches of chromatin at the periphery of the nucleus, which was not observed in control samples (Fig. 1h compared to $1 \mathrm{~g}$ ).

\section{Structural and ultrastructural changes in the $O B$}

TEM observations were performed on each of the three stratified zones of the OB (i.e., the glomerular, the mitral and the granular cell layers) (Fig. 2). When compared to controls, where no morphological changes were observed (Fig. 2a), exposed fetuses exhibited a decrease in the density of axonal endings associated with the presence of areas empty of biological material around glomeruli (Fig. 2b1 and Fig. 2d, see black stars). The periglomerular cells (PG) exhibited cellular hypertrophy, suggesting a "swelling" phenomenon, and their nuclei displayed condensation and marginalization of the chromatin (Fig. 2d, see white arrows). Moreover, the cyto-architecture of the granule cell (Gr) layer, which normally tends to be spatially organized in restricted and well-defined clusters of potentiated mitral-granule cell synapses [65, 66], was altered. Indeed, exposed fetuses showed a disruption of the Gr clusters (Fig. $2 \mathrm{~b} 3$ and Fig. 2f), along with condensation and marginalization of the chromatin in Gr nuclei (Fig. 2f, see white arrows). No major neuroanatomical alteration in the mitral $(\mathrm{Mt})$ cell layer of exposed fetuses was observed (Fig. $2 \mathrm{~b} 2$ compared to Fig. 2a2).

\section{Presence of NP-like particles in the olfactory tissues}

To determine whether inhaled diesel nanoparticles were able to reach fetuses and alter olfactory tissues before birth, ultrathin sections of $\mathrm{OM}$ and $\mathrm{OB}$, collected at gestational day 28 (GD28), were examined by TEM. Particle-like structures (15-20 nm in diameter) were observed in $\mathrm{OM}$ of fetuses from which the mothers were exposed to DE. When present, they were predominantly located in cilia (Fig. 3a) or in the cytoplasm of dendritic knobs (Fig. 3b) of OSN. Interestingly, in cilia, the particle-like structures were found as single, i.e. isolated, particles (Fig. 3b1, white arrows), whereas in the cytoplasm of dendritic knobs, they were concentrated into lysosome-like vesicles (Fig. 3a and 3a1, white arrows). Particle-like structures were not visualized in OEC or OSN axons of exposed fetuses (not shown). In the OB, smaller NP-like particles were observed in lysosome-like vesicles in the cytoplasm of PG cells of exposed fetuses ( $5 \mathrm{~nm}$ in diameter) (Fig. 3c). No particle-like structures were visualized in the other regions of interest or in all control fetuses. 

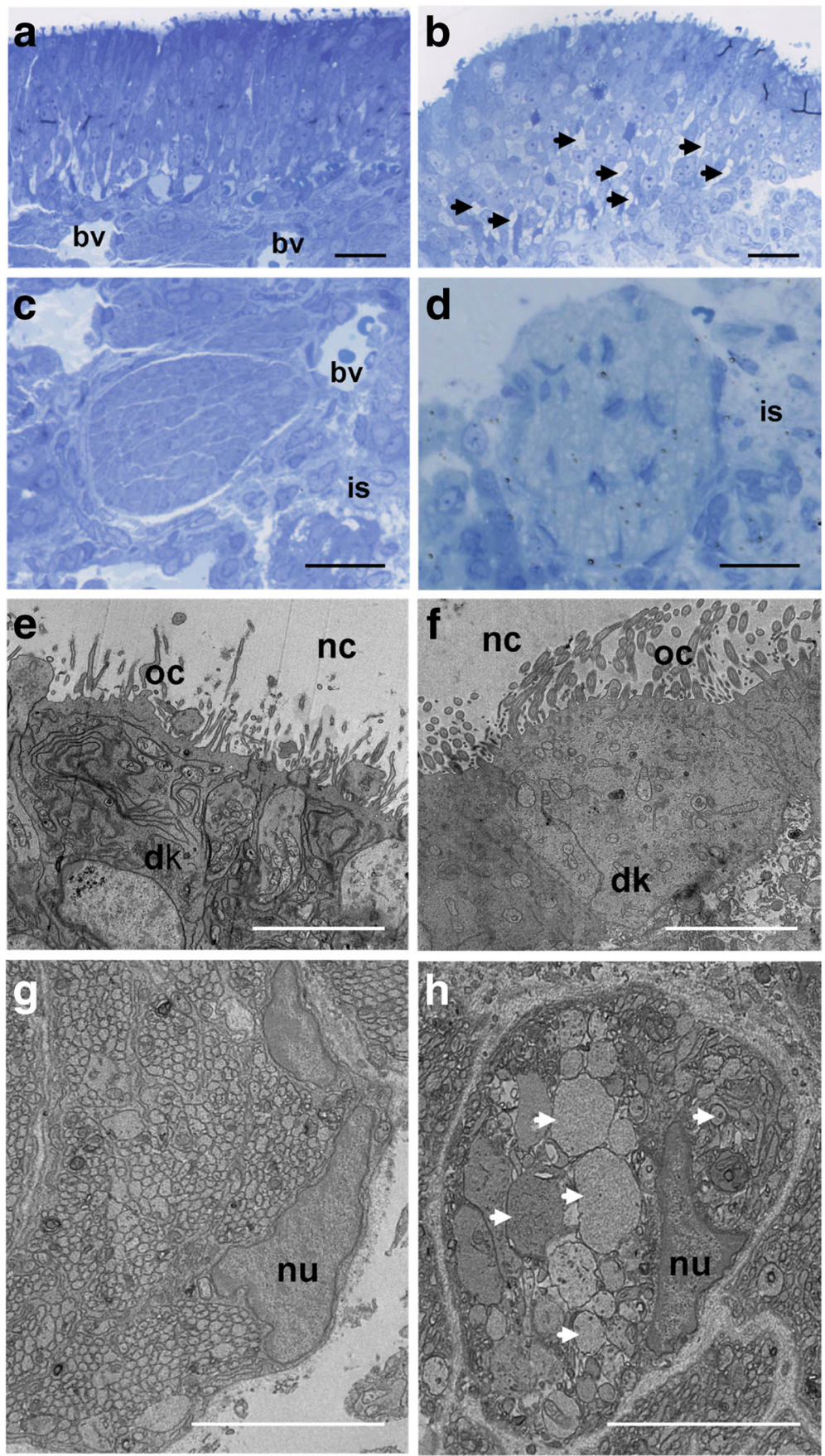

Fig. 1 Effects of DE exposure on the olfactory mucosa. a to $\mathbf{d}$. Micrograph of an olfactory mucosa from control (a, c) and exposed (b, d) GD28 fetuses. The histological coloration reveals the anatomical alterations of the olfactory mucosa (b) and sub-mucosa (d) in exposed GD28 fetuses, compared to control GD28 fetuses (a and $\mathbf{c}$, respectively). Scale bar $=25 \mu \mathrm{m}$. e to $\mathbf{h}$. Electron micrograph of dendritic knobs of an olfactory sensory neuron and of an olfactory axon bundle from control (e and $\mathbf{g}$ ) or exposed ( $\mathbf{f}$ and $\mathbf{h}$ ) GD28 fetuses. Note the decrease of cell organelles in the dendrite knobs of the OSN in exposed GD28 fetuses (f), compared to control GD28 fetuses (e). The white arrows indicate axonal hypertrophy of the olfactory axons of exposed fetuses $(\mathbf{h})$, not observed in control fetuses $(\mathbf{g})$. Note the condensation and marginalization of the chromatin of the ensheating cells of exposed fetuses when compared to controls. Scale bar $=5 \mu \mathrm{m}$. bv = blood vessels; nc: nasal cavity; dk = dendritic knok; oc = olfactory cilia; nu = nucleus, is = intercellular space 

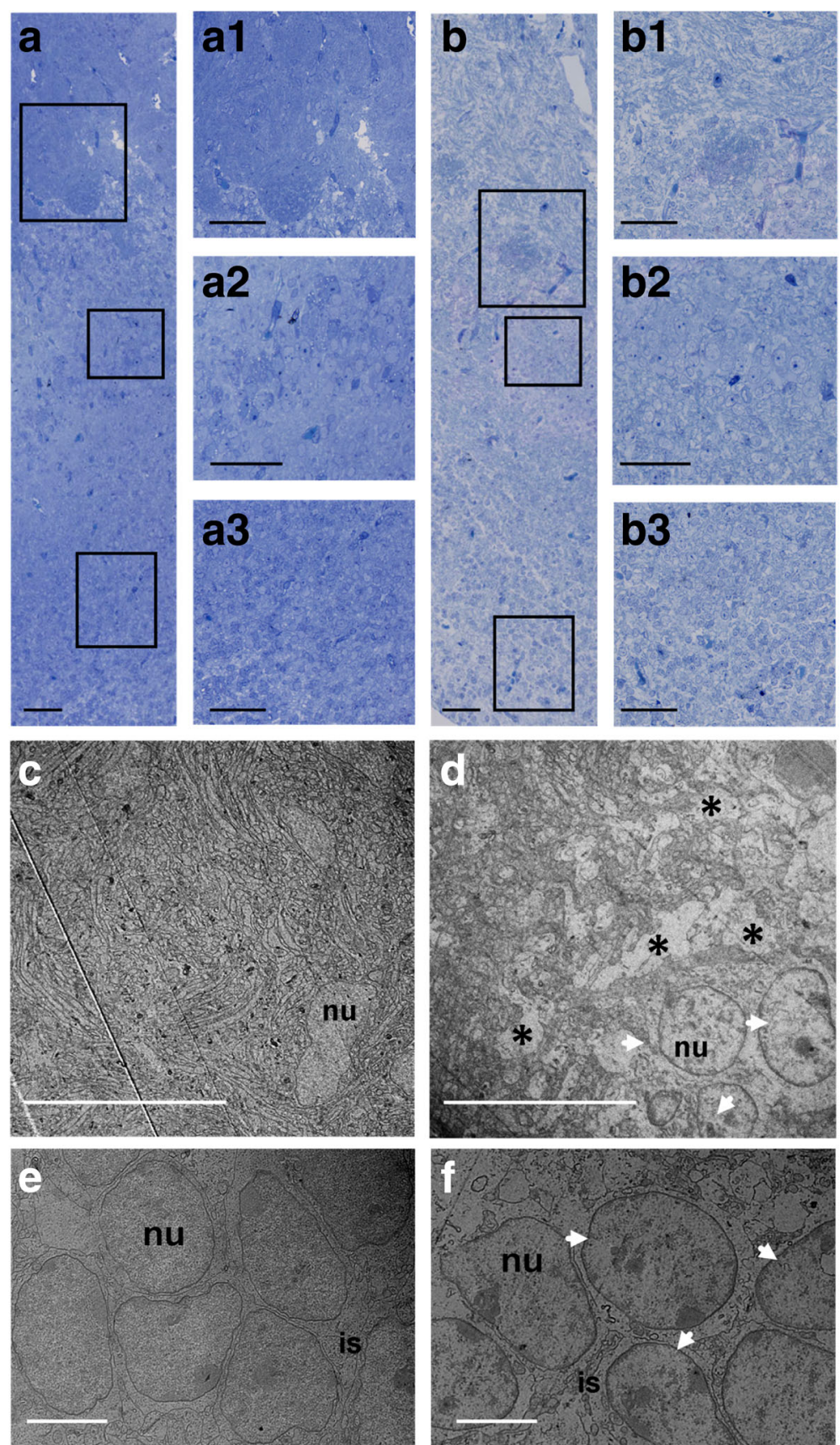

Fig. 2 Effects of DE exposure on the olfactory bulb. a and b. Micrograph of an olfactory bulb section from control (a) and exposed (b) GD28 fetuses. The histological coloration reveals the anatomical alterations of the different layers of the olfactory bulbs of exposed GD28 fetuses (b), compared to control ones (a) and the decrease in axonal ends and the presence of areas empty of biological material around glomeruli of exposed fetuses (b and b1) when compared to controls (a and $\mathbf{a} \mathbf{1}$ ). Granule cells clusters seem disrupted on exposed fetuses (b3) when compared to controls (a3). No anatomical differences in the mitral (Mt) cell layer of exposed fetuses (b2) and control (a2) fetuses were observed. Scale bar: $50 \mu \mathrm{m}$. c and $\mathbf{d}$. Electron micrograph of the glomerular layer of olfactory bulbs from control (c) and exposed (d) GD28 fetuses. Note a significant decrease in axonal endings and the presence of empty areas (black stars) around the glomerulus from exposed fetuses (d), compared to the glomerulus from control fetuses (c). The PG cells of exposed fetuses exhibit a hypertrophy and a condensation and marginalization of their chromatin (white arrows) compared to PG cells from control fetuses. Scale bar: $20 \mu \mathrm{m}$. e and $\mathbf{f}$. Electron micrograph of the granular layer of olfactory bulbs from control and exposed GD28 fetuses. Note the disruption of granular cells clusters, along with a condensation and marginalization of their chromatin, in exposed fetuses (f), compared to the granular clusters from control fetuses $(\mathbf{e})$. Scale bar: $5 \mu \mathrm{m}$. nu= nucleus, is = intercellular space 

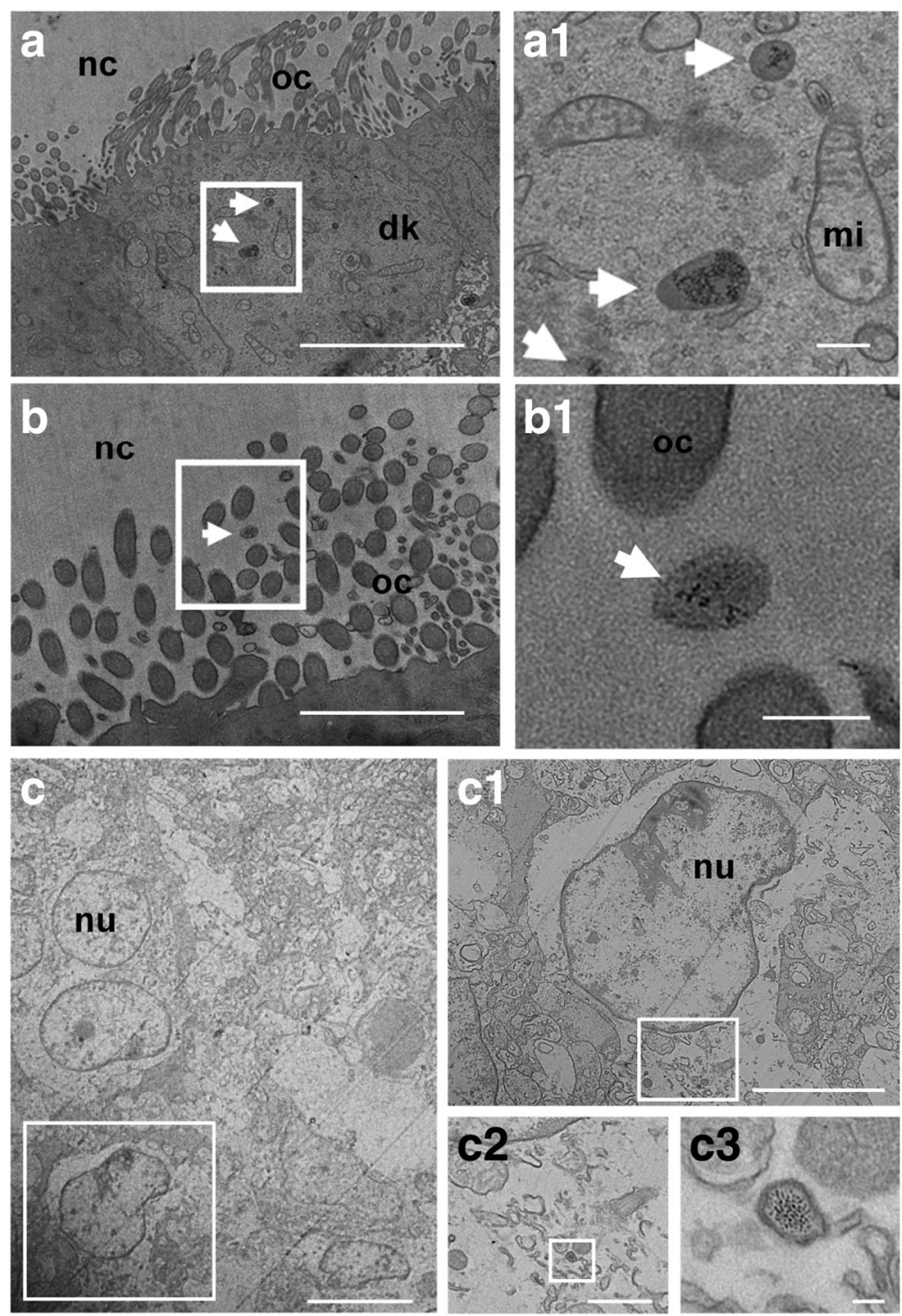

Fig. 3 Electron micrograph showing the presence of particle-like structures in exposed GD28 fetuses' olfactory tissues. $\mathbf{a}$ and $\mathbf{b}$. Electron micrograph of the apical zone of the olfactory epithelium from exposed GD28 fetuses. a. Olfactory sensory neurons cilia with the structure in the framework enlarged at higher magnification (a1). The white arrows point out isolated particle-like structures (15-20 nm in diameter), which appeared inside olfactory cilia or in contact with olfactory cilia. b. Olfactory sensory neurons cytoplasm, with the structure in the white framework at higher magnification (b1). The white arrows point out lysosome-like vesicles containing NP-like particles (15-20 nm in diameter). Scale bars: a and b= $5 \mu \mathrm{m} ; \mathrm{a} 1$ and $\mathrm{b} 1=200 \mathrm{~nm}$. c. Electron micrograph of the olfactory glomerulus from an exposed fetus showing the presence of NP-like particles in the cytoplasm of a PG cell. c1, $\mathbf{c 2}$ and $\mathbf{c} 3$ are enlargements at higher magnification to point out lysosome-like vesicles containing NP-like particles $(5 \mathrm{~nm}$ in diameter). Scale bars: $\mathrm{c} .=10 \mu \mathrm{m} ; \mathrm{c} 1=5 \mu \mathrm{m} ; \mathrm{c} 2=1 \mu \mathrm{m} ; \mathrm{c} 3=50 \mathrm{~nm}$. $\mathrm{nc}=$ nasal cavity; dk= dendritic knok; oc = olfactory cilia;

$\mathrm{nu}=$ nucleus, $\mathrm{mi}=$ mitochondrion

\section{Histochemical analyses of olfactory pathways Monoaminergic content in the olfactory bulb}

In order to highlight potential neurochemical alterations, the tissue contents of the biogenic monoamines serotonin (5-HT), dopamine (DA) and noradrenaline (NA) in the $\mathrm{OB}$ of control and exposed fetuses were analyzed. Concerning the serotoninergic system, neither tryptophan (TRP) nor Kynurenine (K) levels were significantly different from controls (see Table 1). 5-HT levels were decreased in exposed fetuses $(p=0.023)$; the 5 -HT/TRP ratio of exposed fetuses was slightly lower than in controls, although not significant $(p=0.09)$. Concerning the 5-Hydroxyindoleacetic acid (5-HIAA) levels and 5-HIAA/5-HT ratio, no differences were observed between the two groups (Table 1).

For catecholamine levels, neither NA nor its main metabolite 3-Methoxy-4-hydroxyphenylglycol (MHPG) were significantly changed when compared to controls. 
Table 1 Effects of DE exposure on the serotonergic pathway of GD28 fetuses

\begin{tabular}{|c|c|c|c|c|c|c|c|c|c|c|}
\hline & \multicolumn{2}{|l|}{ Control } & \multicolumn{2}{|l|}{ Exposed } & \multicolumn{2}{|c|}{ Effects of DE exposure } & \multicolumn{2}{|c|}{ Effects of Sex } & \multicolumn{2}{|c|}{ Exposure $\times$ Sex } \\
\hline & Male $(n=4)$ & Female $(n=4)$ & Male $(n=4)$ & Female $(n=4)$ & $F(1,15)$ & $p$-value & $F(1,15)$ & $p$-value & $F(1,15)$ & $p$-valu \\
\hline " & $77,941 \pm 4357.6$ & $77,737 \pm 9898.7$ & $66,086 \pm 7164.3$ & $79,000 \pm 7635.3$ & 0.139 & 0.716 & 0.983 & 0.343 & 0.582 & 0.462 \\
\hline $\mathrm{K}(\mathrm{fmol} / \mathrm{mg})$ & $14,844 \pm 689.1$ & $13,875 \pm 1144.6$ & $12,028 \pm 1334.5$ & $12,611 \pm 1312.6$ & 0.669 & 0.431 & 0.000 & 0.995 & 0.049 & 0.829 \\
\hline 5-HT (fmol/mg) & $1718 \pm 228.3$ & $1546 \pm 151.4$ & $1081 \pm 158.8$ & $1187 \pm 133.4$ & 6.972 & $0.023^{*}$ & 0.046 & 0.833 & 0.724 & 0.413 \\
\hline HT/Trp & $0.022 \pm 0.004$ & $0.020 \pm 0.001$ & $0.017 \pm 0.003$ & $0.015 \pm 0.002$ & 3.457 & 0.090 & 0.628 & 0.445 & 0.081 & 0.782 \\
\hline -HIAA (fmol/mg) & $170.0 \pm 39.16$ & $163.8 \pm 32.29$ & $197.9 \pm 73.28$ & $156.4 \pm 18.62$ & 0.244 & 0.631 & 0.199 & 0.664 & 0.136 & 0.720 \\
\hline -HIAA/5-HT & $0.098 \pm 0.016$ & $0.117 \pm 0.011$ & $0.184 \pm 0.056$ & $0.136 \pm 0.023$ & 0.822 & 0.384 & 0.455 & 0.514 & 0.638 & 0.441 \\
\hline
\end{tabular}

Basal rates of Tryptophan (Trp), Kynurenine (K), Serotonin (5-HT) and 5-Hydroxyindoleacetic acid (5-HIAA), along with the correspondent ratios. Results were expressed as fentomoles/milligram of fresh tissues (fmol/mg). Results are shown as mean $\pm \mathrm{SEM}$. ${ }^{*} p<0.05$ represented a significant difference between each group. 5-HT levels were decreased in exposed fetuses compared to controls. No significant difference existed between groups regarding the other variables of interest

However, the MHPG/NA ratio in exposed fetuses was higher when compared to controls $(p=0.027)$ (Table 2). Interestingly, the latter ratio revealed a sex-dependent difference between the two groups $(p=0.04)$ with no interaction between sex and DEP exposure $(p=0.289)$.

Concerning the dopaminergic pathway, DA levels tended to be higher in exposed fetuses $(p=0.088)$. Neither the levels of its metabolites (3,4-Dihydroxyphenylacetic acid, DOPAC and Homovanillic acid, HVA), nor the ratios (HVA/DA and DOPAC/DA) or DA turnover were significantly affected by the gestational exposure (Table 2).

\section{Bulbar intrinsic DA-cell subpopulations}

In order to establish a link between the anatomical and the neurochemical disturbances of the olfactory system observed at GD28, the intrinsic DA-cells subpopulation within the glomerular cell layer was analyzed through the quantification of the Tyrosine Hydroxylase (TH)-specific labeled cells.

There was no significant differences in the number of $\mathrm{TH}^{+}$cells in the fetal OBs between the two groups [means $=(7.12 \pm 0.97) \times 10^{-5}$ vs. $(7.48 \pm 1.40) \times 10^{-5}$ cells / surface unit (a.u) in controls and exposed, respectively; $p=0.79$ )] (Table 3). This result was confirmed with another quantitative estimation using immunofluorescence analysis; the latter study showed no difference in the number of $\mathrm{TH}^{+}$-cells, DAPI ${ }^{+}$-cells or $\mathrm{TH}^{+}$-cell $/ \mathrm{DAPI}^{+}$-cell ratio between the two groups (data not shown).

\section{TH immunochemistry and acetylcholinesterase activity}

Intensity of $\mathrm{TH}$-staining, along with measurements of Acetylcholinesterase (AChE) activity were measured in glomerular cells of the $\mathrm{OB}$ in order to analyze the effect of $\mathrm{DE}$ exposure on the neuromodulatory inputs to the $\mathrm{OB}$ (Fig. 4). TH analysis did not show any significant difference between the two groups $(p=0.143)$ (Fig. 4a). The statistical analysis of AChE activity (Fig. 4b) did not reveal any significant effect of DEP exposure $(p=0.942)$. However, we observed a sex-dependent difference between the two groups $(p=0.013)$, and an interaction between fetus sex and maternal DEP exposure $(p=0.033)$ (Table 4$)$. This result, thus, highlights a sex-dependent vulnerability upon DEP exposure, with males presenting a decrease and females presenting an increase of AChE activity.

\section{Olfactory-guided behavior is disturbed by DEP exposure at PND2}

In order to highlight a possible connection between the anatomical and the neurochemical disturbances observed in GD28 and putative early olfactory behavioral alterations, a 2MB2 odor-guided behavior test was run in PND2 pups born to exposed or non-exposed dams.

Pearson's Chi-square analysis indicated that the observed percentage of positive responses to $2 \mathrm{MB} 2$ in control pups (66\%) was not significantly different from previous reports [67] (Pearson's Chi-square, $\mathrm{df}=0.5269 ; p=0.4679$ ) (Fig. 5, $60 \%$ of expected positive response, dotted line), but it was significantly lower in exposed pups (41\%) (Pearson's Chi-square, $\mathrm{df}=9.1667 ; p=0.0025)$. Interestingly, the percentage of positive responses to $2 \mathrm{MB} 2$ in exposed pups was significantly lower than in control pups (Pearson's Chi-square, $\mathrm{df}=7.032 ; p=0.008$ ) (Fig. 5).

\section{Discussion}

Using the animal model of controlled nose-only inhalation developed to analyze feto-placental development [62], we have shown that maternal exposure to DE throughout gestation leads to an accumulation of particle-like structures in fetal olfactory tissues, which appears to be associated with alterations in the neuroanatomical organization of this system. Moreover, such DE exposure affects monoaminergic neurotransmission in the $\mathrm{OB}$ and the olfactory-based behaviors connected with nutrient intake at birth. To our knowledge, this is the first study assessing the neuroanatomical nose-brain continuum around birth, even though a direct link between the anatomical and neurochemical disturbances of the olfactory system observed at the fetal stage and the behavioral alterations registered in postnatal early life remains to be demonstrated. These data confirm and expand previous results 
Table 2 Effects of DE exposure on the catecholamine system of GD28 fetuses

\begin{tabular}{|c|c|c|c|c|c|c|c|c|c|c|}
\hline & \multicolumn{2}{|l|}{ Control } & \multicolumn{2}{|l|}{ Exposed } & \multicolumn{2}{|c|}{ Effects of DE exposure } & \multicolumn{2}{|c|}{ Effects of Sex } & \multicolumn{2}{|c|}{ Exposure $\times$ Sex } \\
\hline & Male $(n=4)$ & Female $(n=4)$ & Male $(n=4)$ & Female $(n=4)$ & $F(1,15)$ & $p$-value & $F(1,15)$ & $p$-value & $F(1,15)$ & $p$-value \\
\hline $\mathrm{DA}(\mathrm{fmol} / \mathrm{mg})$ & $274.9 \pm 27.59$ & $276.1 \pm 37.85$ & $389.7 \pm 45.00$ & $341.9 \pm 41.79$ & 3.502 & 0.088 & 0.525 & 0.484 & 0.262 & 0.619 \\
\hline DOPAC (fmol/mg) & $212.1 \pm 56.13$ & $212.1 \pm 43.34$ & $346.0 \pm 122.38$ & $460.3 \pm 84.89$ & 2.451 & 0.146 & 0.453 & 0.515 & 1.308 & 0.277 \\
\hline HVA (fmol/mg) & $222.6 \pm 32.11$ & $280.4 \pm 32.21$ & $514.1 \pm 71.17$ & $412.0 \pm 134.76$ & 2.761 & 0.125 & 0.357 & 0.562 & 0.311 & 0.588 \\
\hline DOPAC/DA & $0.789 \pm 0.240$ & $0.789 \pm 0.147$ & $0.857 \pm 0.247$ & $1.33 \pm 0.104$ & 0.738 & 0.409 & 1.644 & 0.226 & 0.612 & 0.115 \\
\hline HVA/DA & $0.810 \pm 0.084$ & $1.066 \pm 0.214$ & $1.315 \pm 0.068$ & $1.158 \pm 0.247$ & 0.411 & 0.534 & 0.016 & 0.901 & 0.612 & 0.451 \\
\hline$(\mathrm{DOPAC}+\mathrm{HVA}) / \mathrm{DA}$ & $1.599 \pm 0.290$ & $1.855 \pm 0.303$ & $2.173 \pm 0.307$ & $2.488 \pm 0.348$ & 0.854 & 0.375 & 0.879 & 0.369 & 0.557 & 0.471 \\
\hline $\mathrm{NA}(\mathrm{fmol} / \mathrm{mg})$ & $414.7 \pm 14.90$ & $488.8 \pm 45.88$ & $304.0 \pm 54.32$ & $437.1 \pm 145.76$ & 1.945 & 0.191 & 1.808 & 0.206 & 0.431 & 0.525 \\
\hline MHPG (fmol/mg) & $126.9 \pm 17.15$ & $94.45 \pm 24.17$ & $135.0 \pm 31.76$ & $137.9 \pm 78.42$ & 0.613 & 0.450 & 0.099 & 0.759 & 0.071 & 0.794 \\
\hline MHPG/NA & $0.304 \pm 0.36$ & $0.192 \pm 0.039$ & $0.469 \pm 0.102$ & $0.277 \pm 0.091$ & 6.466 & $0.027^{*}$ & 5.416 & $0.040^{*}$ & 1.241 & 0.289 \\
\hline
\end{tabular}

Basal rates of Dopamine (DA), 3,4-Dihydroxyphenylacetic acid (DOPAC), Homovanillic acid (HVA), Noradrenalin (NA), and 3-Methoxy-4-hydroxyphenylglycol (MHPG), along with the correspondent ratios. Results were expressed as fentomoles/milligram of fresh tissues (fmol/mg). Results are shown as mean \pm SEM. ${ }^{*} p<$ 0.05 represented a significant difference between each group. Neither NA, nor its main metabolite MHPG, was significantly changed when compared to controls. However, the MHPG/NA ratio in exposed fetuses was higher when compared to controls. DA levels were slightly higher in exposed fetuses, even if not significant. No significant difference existed between groups regarding the other variables of interest

suggesting that UFPM are of great concern given their particular characteristics (i.e. size, surface charge, surface coating, chemical composition,..), which have been argued to determine their capacity to access organs and exert tissue alterations [68-73]. They thus are suspected to represent a class of particles with serious health effects compared to PM10 and PM2.5 [74, 75], and for which strong epidemiological evidence is not available yet due to the lack of exposure data [76]. Although we used a polluted air enriched in nanosized particles, we cannot exclude that the observed effects are also linked to the presence of other chemical components, known to be associated to neurodevelopmental deficits in several cases of gestational exposition [77, 78]. The inhalation model of exposure was monitored for volatile compounds including carbon monoxide and nitric oxide products with levels of 7 and $36 \mu \mathrm{g} / \mathrm{m}^{3}$, respectively. Such values were largely under the levels used for traffic regulation in urban areas, suggesting the observed effects on olfactory system to be more related to NP exposure than to gaseous components. $\mathrm{DE}$ is composed of hundred chemical substances including among them Polycyclic Aromatic Hydrocarbons which have been demonstrated to be neurotoxic [79]. Whereas PAHs may contribute for a part to the effects observed here, it was not possible in the present study to measure their levels of concentration in the brain and the olfactory bulb.
Gestational inhaled diesel engine exhaust can reach fetal olfactory structures

We have demonstrated the presence of NP-like structures in various regions of the fetal olfactory system, from the periphery to the central $\mathrm{OB}$ structures, whose diameters were estimated between 5 and $20 \mathrm{~nm}$ depending on the structure (mean diameter of inhaled particles during exposure was $69 \mathrm{~nm}$ ). To our knowledge, the current results demonstrate for the first time a possible nasal route of fetal exposure after maternal nose-only inhalation of DE in controlled conditions mimicking the fetal exposure encountered by humans in everyday life. So far, most studies describing particles in olfactory tissues have been performed in conditions of sustained exposure to non-controlled air pollutants, either in a chronic or acute highly concentrated environment in rodents [80, 81], dogs [13] or human [15]. However, it was not formally confirmed that these particles originated from the diesel exposure, since further analyses to determine the chemical composition of these NP-like structures are hindered by the important carbon content of DE. Moreover, so far, it has not been possible to study the chemical composition of their corona, although it could provide insight into mechanisms by which these particles access biological tissues [82, 83].

Even if it was not demonstrated how the inhaled particles can translocate to the fetal olfactory system, it is quite likely that the NP could have been transported to

Table 3 Quantification of TH-labeled cell number in GD28 olfactory bulbs

\begin{tabular}{|c|c|c|c|c|c|c|c|c|c|c|}
\hline & \multicolumn{2}{|l|}{ Control } & \multicolumn{2}{|l|}{ Exposed } & \multicolumn{2}{|c|}{ Effects of DE exposure } & \multicolumn{2}{|c|}{ Effects of Sex } & \multicolumn{2}{|c|}{ Exposure $\times$ Sex } \\
\hline & Male $(n=4)$ & Female $(n=4)$ & Male $(n=8)$ & Female $(n=5)$ & $F(1,20)$ & $p$-value & $F(1,20)$ & $p$-value & $F(1,20)$ & $p$-value \\
\hline $\begin{array}{l}\text { TH-labeled cell }(10 \times-5 \text { cells / } \\
\text { surface unit, a.u) }\end{array}$ & $7.99 \pm 1.49$ & $6.25 \pm 1.48$ & $6.57 \pm 1.91$ & $8.94 \pm 2.41$ & 0.074 & 0.790 & 0.020 & 0.888 & 1.013 & 0.329 \\
\hline
\end{tabular}

Quantification of the number of $\mathrm{TH}+$ labeled cells in control and exposed samples. ${ }^{*} p<0.05$. No significant difference existed between groups 


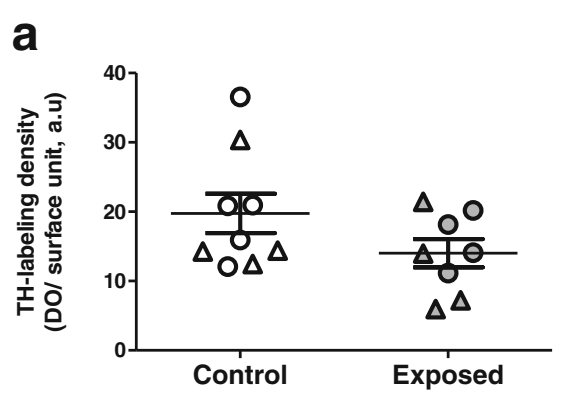

O Control male (5)

$\triangle$ Control female (4) b

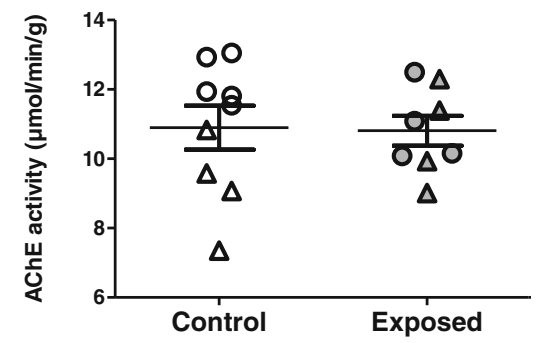

O Exposed male (4)

$\triangle$ Exposed female (4)

Fig. 4 Quantification of dopaminergic and cholinergic inputs into GD28 olfactory tubercle. a Relative mean density of TH+ labeled fibers in the olfactory tubercle. The quantitative estimation did not show any significant difference between the two groups. b Relative means density of AChE activity in the olfactory tubercle. There was no significant difference between the two groups regarding the DE exposure. However, we observed a sex-dependent difference between the two groups, which interacted significantly with DE exposure

the fetal olfactory organs through the systemic circulation since Valentino and colleagues have shown, on the same animals, that NPs were able to cross the maternal lung barrier and reach fetal erythrocytes across the placenta $[62,64]$. Another possibility to explain the presence of NP-like particles at the level of the olfactory cilia bathing the nasal mucus is a direct translocation of NP from the amniotic fluid. It would be interesting to confirm the presence of NP in the amniotic liquid of exposed dams, as observed for tobacco substances in pregnant smoking women [84], in order to have an insight on the mechanisms by which fetuses are exposed to the particles, all mechanisms not being exclusive.

Interestingly, even if we observed free NP-like structures in the olfactory cilia, most were concentrated in lysosome-like vesicles throughout the olfactory structures. Such vesicles were not observed in the placenta of exposed rabbits, suggesting that the process might be specific to olfactory structures [62]. Whether they are associated with cell-specific uptake mechanisms such as lysosomal deposition or caveolae remains to be characterized. As UFPM have already been observed in caveolae of endothelial cells and in luminal red blood cells in myocardial capillaries of 1-year-old dogs from highly polluted cities [85], our observations also fit with an ongoing hypothesis of transportation of inhaled NPs through a process called "transcytosis" [82].

\section{A controlled repeated gestational exposure to DE alters the bulbar neuromodulation in exposed fetuses}

We observed disturbances in the nerve fascicles arising from the olfactory epithelium, along with a decrease in axonal density and in cellular components around glomeruli in exposed fetuses. Such structural alterations are unlikely to be the consequence of a peripheral perturbation in the number and/or guidance of OSN projections to the $\mathrm{OB}$, since no modification in the density of olfactory cells was observed in the OM. Interestingly, the observed heterogeneous hypertrophy of OSN axons was reminiscent of a "swelling" phenomenon, suggesting the onset of inflammatory processes of the cells, that has been shown in other neuronal cells following gestational DE exposure [37, 39]. Furthermore, we noticed evidence of ultrastructural modifications of nuclei in various olfactory cell types, suggesting early signs of cell death in $\mathrm{OM}$ and $\mathrm{OB}$. Altogether, these observations suggest that DE impact the cellular homeostasis in olfactory structures at a timing encompassing an important window of developmental neurogenesis and could, thus, interfere with fetal neurobiological development.

Table 4 Quantification of dopaminergic and cholinergic inputs in GD28 olfactory tubercles

\begin{tabular}{|c|c|c|c|c|c|c|c|c|c|c|}
\hline & \multicolumn{2}{|l|}{ Control } & \multicolumn{2}{|l|}{ Exposed } & \multicolumn{2}{|c|}{ Effects of DE exposure } & \multicolumn{2}{|c|}{ Effects of Sex } & \multicolumn{2}{|c|}{ Exposure $\times$ Sex } \\
\hline & Male $(n=4)$ & Female $(n=4)$ & Male $(n=8)$ & Female $(n=5)$ & $F(1,16)$ & $p$-value & $F(1,16)$ & $p$-value & $F(1,16)$ & $p$-value \\
\hline $\begin{array}{l}\text { TH-labeling density (DO/ } \\
\text { surface unit, a.u) }\end{array}$ & $21.27 \pm 4.65$ & $17.86 \pm 4.84$ & $15.89 \pm 2.34$ & $12.14 \pm 4.11$ & 2.461 & 0.143 & 1.080 & 0.319 & 0.001 & 0.980 \\
\hline AChe activity $(\mu \mathrm{mol} / \mathrm{min} / \mathrm{g})$ & $12.25 \pm 0.34$ & $9.21 \pm 0.83$ & $10.96 \pm 0.85$ & $10.66 \pm 0.85$ & 0.006 & 0.942 & 8.462 & $0.013^{*}$ & 5.773 & $0.033^{*}$ \\
\hline
\end{tabular}

Relative mean density of $\mathrm{TH}+$ labeled fibers in the olfactory tubercle. The quantitative estimation did not show any significant difference between the two groups Relative mean density of AChE activity in the olfactory tubercle. There is no significant difference between the two groups regarding the DE exposure. However, we observed a sex-dependent difference between the two groups, which interacted significantly with DEP exposure. ${ }^{*} p<0.05$ 


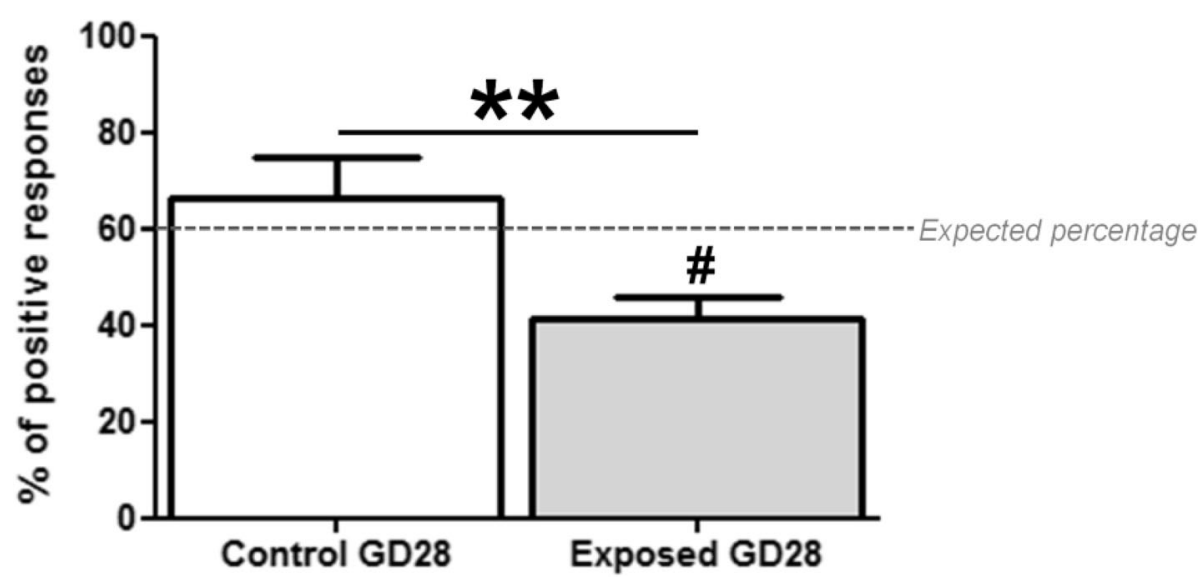

Fig. 5 Percentages of positive behavioral responses following to the presentation of the rabbit mammary pheromone 2MB2. Results are expressed as mean \pm SEM for each group. \# $p<0.01$ represented a significant difference between the groups and the expected percentage (60\%). The percentage of positive responses in exposed fetuses (41\%) was significantly lower, whereas that of control fetuses (66\%) was not significantly different. ${ }^{* *} p<0.01$ represented a significant difference between the two groups. The comparison of the percentages showed a significant difference between the two groups

Associated with these ultrastructural alterations, we observed bulbar neuromodulatory disturbances, with a decrease in 5-HT levels and an increase in NA turnover in the OB of exposed fetuses. Moreover, a sex-dependent alteration in cholinergic inputs to the OB was shown. Furthermore, although neither bulbar intrinsic DA-cell subpopulations nor dopaminergic projection inputs to the OB seemed to be affected by DE exposure, a tendency of increase in bulbar DA levels was observed.

Our data thus suggest that alterations of the centrifugal olfactory input precede a bulbar dopamine disturbance, which is not inconsistent with an ongoing hypothesis suggesting that the bulbar dopaminergic alterations are a compensatory plastic response following reduced neuromodulatory innervations [60].

Given that the noradrenergic, serotoninergic, dopaminergic and cholinergic projections originate from central structures, the neurochemical alterations might not only concern olfactory processes, but also more integrative ones. Such early perturbations on fetal neural network might also persist later in life and lead to neurocognitive disorders related to monoaminergic systems [41-45, 86]. Further analyses need to be performed in order to see if and how DE exposure alters the modulatory pathways in other brain regions and, therefore, to further substantiate the toxic effects of DE inhalation on the CNS.

Interestingly, sex-dependent neurochemical disturbances in the $\mathrm{OB}$ and $\mathrm{Tu}$ of exposed fetuses were observed. Such a possible link between gestational air pollution exposure and sex-dependent alterations of the CNS has already been pointed out in recent studies, with males being often more affected by environmental insults than females [34, 47, 48, 87]. However, to our knowledge, this is one of the rare studies comparing monoamine fetal disturbances between sexes. Indeed, most studies have been performed on in utero exposed male adult mice only to show imbalances in the monoaminergic systems related to various neurocognitive disorders [41-44]. Moreover, behavioral evaluations on both male and female mice have shown that prenatal exposure to UFPM induces more severe consequences on males [88]. Furthermore, male offspring prenatally exposed to both airborne pollution and maternal stress during late gestation were cognitively impaired, suggesting that males could be more sensitive to the adverse CNS changes after DE exposure [34]. Nevertheless, the PM-induced sex-dependent CNS changes are quite complex [88] and require further investigation.

Overall, our data suggest that early life exposure to airborne pollution may affect the fetal brain development and might predispose the progeny to neurodevelopmental diseases later in life, which is in agreement with the recent work of Calderon-Garcidueñas and colleagues in children and young adults [89].

\section{A controlled repeated gestational exposure to DE leads to disturbance in odor sensitivity in rabbit offspring} The behavioral performance of rabbit neonates clearly revealed early olfactory behavioral alterations at birth following a repeated gestational exposure to DE. Rabbit newborns, for that matter, constitute an interesting model system given that they display innate behaviors mainly governed by olfactory cues to feed at this stage, through the stereotyped behavioral pattern in response to the rabbit mammary pheromone 2-Methyl-3-butyn-2-ol [90, 91] through the main olfactory system. In utero DE exposed pups exhibited a decreased response to 2MB2, tested at a single commonly used concentration [90]. Since the 
newborn response to the mammary pheromone follows a concentration-dependent bell-shaped curve, with an optimal responsiveness between $10^{-8}$ and $10^{-6} \mathrm{~g} / \mathrm{ml}$ [67], the low response at $5.10^{-8} \mathrm{mg} / \mathrm{ml}$ could be due to a shift of the bell-shaped curve response to lower or higher concentrations, thus indicating either a worsened or a better olfactory threshold in exposed animals. However, the morphological and neurochemical alterations observed at GD28 in the main olfactory system favors an impairment of the neurobehavioral development of newborns, even though a direct link between the anatomical and functional disturbances of the olfactory system observed in GD28 and the behavioral alterations registered at PND2 remains to be demonstrated [90, 92]. Moreover, it is possible that the structural and neurochemical alterations not only concern olfactory processes, but also more integrative ones, since gestational exposure to DE was demonstrated to induce various neurocognitive disorders related to monoaminergic systems [41-45, 86]. In fact, because of the known anatomical and functional continuum between the olfactory system and the rest of the brain, there could be olfactory transport of toxic materials, including particulate matter, into various regions of the brain connected with several aspects of other motivated behaviors [15, 93, 94]. Besides, no difference in the growth of pups was observed until weaning (Charlier M. and Rousseau D., unpublished data) suggesting that exposed pups have an efficient suckling behavior, despite the modification in $2 \mathrm{MB} 2$ pheromone response (not shown).

\section{Conclusion}

The present study describes the neurodevelopmental toxic effects on the olfactory system of a controlled daily gestational exposure to DE on a human hemodichorial placentation animal model in conditions mimicking urban human exposure. Overall, our findings strongly suggest that prenatal exposure to $\mathrm{DE}$ in rabbit fetuses allows translocation of nanoparticles towards fetal nervous system structures with potential pathological effects on the nervous system. Such exposure affects the neuro-olfactory development of rabbit offspring, and alters early olfactory-based behaviors. Because of the known anatomical and functional continuum between the olfactory system and the rest of the brain, such early alterations could be indicative of disturbances in higher integrative structures. These data confirmed that prenatal phase should be considered as an important window for brain development, during which there is an elevated susceptibility to environmental insults [24, 78, 95]. Preventing exposure of pregnant women to a polluted environment should, therefore, be taken into account by public authorities.

\section{Methods}

\section{Animal exposure}

The present study is part of a larger program funded by the ANR (ANR-13-CESA-0011-EPAPP). The experimental procedure for animal exposure has been previously detailed and approved by the French ethical committee $\mathrm{N}^{\circ} 45$ under the number $\mathrm{N}^{\circ} 12 / 102$ [62]. Briefly, twenty-eight pregnant New-Zealand white female rabbits (INRA1077 line, 1-year old) (F0) were exposed by nose-only inhalation to either clean air (control group; $N=14$ ) or diluted DE $\left(1 \mathrm{mg} / \mathrm{m}^{3}\right)$ (exposed group; $N=14$ ) for $2 \mathrm{~h} /$ day, 5 days/week, from gestational day 3 (GD3) to day 27 (i.e., 20 days over a 31-day gestation) (Fig. 6, adapted from [62]).

$\mathrm{DE}$ exposure was performed with the Mobile Ambient Particle Concentrator Exposure Laboratory [96], connected to a $25 \mathrm{KVA}$ Loxam engine, with a $500 \mathrm{~nm}$ particle filter. The measured components of the $\mathrm{DE}$ exposure mixture used in the present experiment were analyzed elsewhere and their NP content displayed an average size of $69 \mathrm{~nm}$ [62].

\section{Experimental procedure}

At GD28, 12 dams ( $N=5$ controls; $N=7$ exposed) were euthanized and their fetuses counted, weighed individually and euthanized by decapitation. Skilled staff using well-maintained equipment ensured the rapid death of each animal and carried out the manipulation under appropriate conditions. All experiments were performed by confirmed experimenters or with their help. F1 fetuses were sexed by visual observation of their internal genital organs (confirmed by a second sexing by qPCR approach). Fetal olfactory mucosa (OM), hemi-olfactory bulbs (OB) and whole brains were dissected and nervous tissues were weighed. We observed no difference in total brain or $\mathrm{OB}$ weight between exposed and not exposed fetuses (not shown). Random samples of the latter structures were snap frozen in liquid nitrogen or isopentane for subsequent anatomical and chemical measures. Non-frozen $\mathrm{OB}$ and $\mathrm{OM}$ were randomly assigned to histological, immunological or transmission electron microscopy (TEM) experiments.

Eighteen exposed or control dams $(N=9$ in each group) gave birth to $\mathrm{F} 1$ offspring. The day of birth was settled as postnatal day 0 (PND0). At PND2, offspring were examined for their odor-guided behavior in response to the presentation of the rabbit mammary pheromone 2-Methyl-3-butyn-2-ol (2MB2) as published elsewhere [90]. They were then raised in control conditions in order to study long-term and intergenerational effects of this gestational DE exposure (as described previously [62]). 


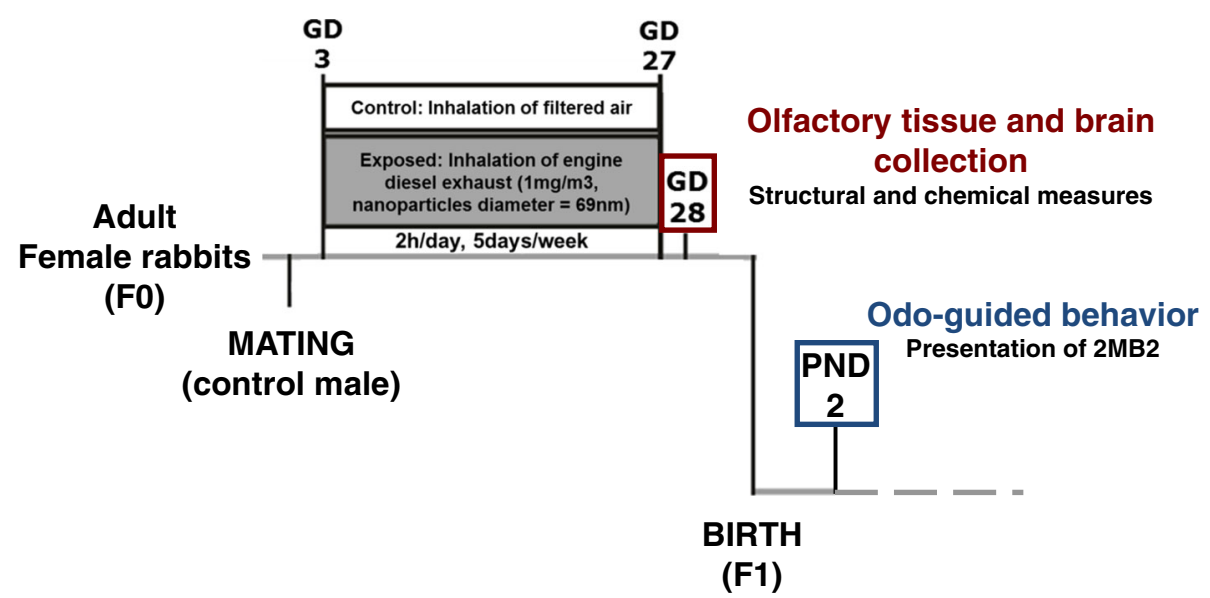

Fig. 6 Experimental protocol. Pregnant New-Zealand white female rabbits were exposed by nose-only inhalation to either clean air (control group; $N=14$ ) or DE containing diluted DEP $\left(1 \mathrm{mg} / \mathrm{m}^{3}\right.$ ) (exposed group; $N=14$ ) for $2 \mathrm{~h} /$ day, 5 days/week, from gestational day 3 (GD3) to day 27. At $\mathrm{GD} 28,12$ dams ( $N=5$ controls; $N=7$ exposed) were euthanized and their fetuses sacrificed by decapitation. Fetal olfactory mucosa (OM), hemi-olfactory bulbs (OB) and whole brains were dissected. Random samples of the latter structures were chosen for structural and chemical measures Eighteen exposed or control dams ( $N=9$ each) gave birth to F1 offspring. The day of birth was settled as postnatal day 0 (PND0). At PND2, offspring were examined for their odor-guided behavior in response to the presentation of the rabbit mammary pheromone 2-Methyl-3-butyn-2-ol (2MB2). They were then raised in control conditions in order to study long-term and intergenerational effects of this gestational DE exposure.

\section{Olfactory system measurements}

\section{TEM analysis of the olfactory system}

Fetal $\mathrm{OM}$ and $\mathrm{OB}$ samples collected randomly from 2 exposed and 2 control dams (one male and one female per litter; $N=4$ in each experimental group) were fixed in $2 \%$ glutaraldehyde overnight at $4{ }^{\circ} \mathrm{C}$. Samples were contrasted with $0.5 \%$ OTE (Oolong Tea extract) in cacodylate buffer $\left(20 \mathrm{~min}, 37^{\circ} \mathrm{C}\right)$, fixed in $1 \%$ OsO4 containing $1.5 \%$ ferrocyanide $\left(20 \mathrm{~min}, 37^{\circ} \mathrm{C}\right)$, dehydrated using a series of ethanol dilutions $\left(5 \mathrm{~min}\right.$ each, $37^{\circ} \mathrm{C}$ ) and acetone $\left(10 \mathrm{~min}, 37^{\circ} \mathrm{C}\right)$ and embedded in Epon resin using a microwave $\left(60 \mathrm{~min}, 50{ }^{\circ} \mathrm{C}\right)$. Sections $(1 \mu \mathrm{m})$ were stained with methylene Blue/Azure II and examined with an Olympus microscope. Ultrathin sections $(75 \mathrm{~nm})$ were stained with lead citrate and examined with HITACHI HT7700 transmission electron microscope at $80 \mathrm{KeV}$ on MIMA2 platform (https://www6.jouy.inra.fr/mima2). For each sample, several blocks were cut $(N=2)$ and at least 4 grids/block were observed by a blind experimenter. Images were selected to show a representative view of the alterations in the olfactory tissues.

\section{Bulbar HPLC dosage}

The levels of DA, 5-HT, NA, and their respective metabolites were quantified using high performance liquid chromatography (HPLC) on crushed OB samples. Prior to analysis, randomly chosen right OBs from control or exposed fetuses ( $N=4$ male and $N=4$ female per group) were weighted, crushed in $400 \mu \mathrm{L}$ of $0.2 \mathrm{M}$ perchloric acid and centrifugated at $22,000 \mathrm{~g}$ for $20 \mathrm{~min}$ at $4{ }^{\circ} \mathrm{C}$. The supernatants were collected and filtered through a $10 \mathrm{kDa}$ membrane (Nanosep, Pall) by centrifugation at $7000 \mathrm{~g}$ (30 $\min )$. Then, a $20 \mu \mathrm{L}$ aliquot of each sample was analyzed for 5-HT and 5-HIAA by fluorometric detection (Kema). The amounts of catecholamines (DA and NA) and of their main metabolites (DOPAC and HVA for DA; MHPG for noradrenaline) were measured by electrochemical detection on a serial array of coulometric flow-through graphite electrodes (CoulArray, ESA). Analysis, data reduction, and peak identification were fully automated. Results were expressed as femtomoles/milligram of fresh tissues [97, 98]. Results are shown as mean \pm SEM.

\section{Bulbar tyrosine hydroxylase immunohistochemistry and image analysis}

Randomly chosen fetal OBs $(N=4$ male and $N=4$ female control fetuses; $N=8$ male and $N=5$ female exposed fetuses) were fixed during $24 \mathrm{~h}$ in $4 \%$ paraformaldehyde (PFA) at $4{ }^{\circ} \mathrm{C}$ and cryoprotected with a $30 \%$ sucrose solution in PBS for 3 days at $4{ }^{\circ} \mathrm{C}$. Tissues were thereafter embedded in tissue-TEK and store at $-80{ }^{\circ} \mathrm{C}$.

Serial sections $(16 \mu \mathrm{m})$ of GD28 OBs were mounted on Super Frost slides (Roth-Sochiel, Lauterbourg, France) and kept at $-80{ }^{\circ} \mathrm{C}$ until use. The slices were dried at room temperature for $20 \mathrm{~min}$. The endogenous peroxidase activity was inhibited by $\mathrm{H}_{2} \mathrm{O}_{2}(0.3 \%)$ for $30 \mathrm{~min}$. Sections were then blocked with $1 \%$ BSA and normal horse serum for $30 \mathrm{~min}$ and incubated overnight at $4{ }^{\circ} \mathrm{C}$ in presence of mouse monoclonal primary anti-tyrosine hydroxylase antibody (TH, catalogue \#T1299; Sigma, St. Louis, MO, 1:5000 in $0.3 \%$ Triton X-100). Samples were then incubated for $30 \mathrm{~min}$ at room temperature with biotinylated 
anti-mouse IgG (Vectastain Elite ABC Kit, PK-6102, Vector laboratories, Burlingame, USA), followed by avidin-biotin-peroxidase complex (Vectastain Elite ABC Kit, PK-6102, Vector laboratories, Burlingame, USA) that was used according to the supplier's instructions. The slices were revealed for 10 min using 3',3-diaminobenzidine (DAB) substrate kit for visualization (SK-4100, Vector laboratories, Burlingame, USA), resulting in a gray-black reaction product. The reaction was stopped with deionised water. The sections were then dried and coverslipped with Eukitt mounting medium (catalogue \#03989; Sigma, St. Louis, MO) and kept in the dark until image capture.

Stained sections were examined using a light upright optical microscope (Nikon Eclipse Ni-U) at $4 \mathrm{x}$ and 40x magnifications (Nikon France, Champigny-sur-Marne, France) and quantified using the NIS-Elements $\mathrm{Br}$ software (Nikon). A blind experimenter quantified all images.

Quantification of the number of $\mathrm{TH}$-immunoreactive cells $\left(\mathrm{TH}^{+}\right)$was carried out by examination of 2 non-adjacent sections per fetus photographed with the $4 \mathrm{x}$ objective, on 4 independent immunohistochemistry experiments. After application of an optimal threshold $([30,170])$ to exclude the non-specific labeling and the background, the quantification of $\mathrm{TH}$-immuno-labeled cells was fully automated. The number of $\mathrm{TH}^{+}$cells was then normalized to the selected area (ROI) size. Two independent ROIs per section were analyzed (i.e., four measures per animal).

\section{Brain histological and histochemical measurements Tissue preparation}

Randomly chosen fetal brains $(N=5$ male and $N=4$ female control fetuses; $N=4$ male and $N=4$ female exposed fetuses) were rapidly frozen in cooled isopentane at $-34{ }^{\circ} \mathrm{C}$ and subsequently stored at $-80^{\circ} \mathrm{C}$. Twenty $\mu$ m-thick coronal sections were serially cut on a cryostat, collected on gelatin-chrome alum-coated slides and stored at $-80^{\circ} \mathrm{C}$ until histological and histochemical processing.

\section{Brain tyrosine hydroxylase and tryptophan hydroxylase immunohistochemistry and image analysis}

Slices were dried at room temperature for $20 \mathrm{~min}$. Sections were incubated in $4 \%$ formaldehyde for $30 \mathrm{~min}$. The immunohistochemical protocol has been described above (5.3.3). Sections were incubated overnight at $4{ }^{\circ} \mathrm{C}$ in presence of mouse monoclonal primary anti-tyrosine hydroxylase antibody (TH, catalogue \#T1299; Sigma, St. Louis, MO, 1:5000 in 0.3\% Triton X-100) or in presence of mouse monoclonal primary anti-tryptophan hydroxylase antibody (TrpH, catalogue \#T0678; Sigma, St. Louis, MO, 1:2000 in 0.3\% Triton X-100). The slices were revealed for 3 min using DAB substrate kit.

Analysis of $\mathrm{TH}$ and $\mathrm{TrpH}$ stained sections was carried out with a BIOCOM computer-assisted image analysis system (Les Ulis, France), in which optical density readings were performed. In absence of an available rabbit brain atlas, anatomical structures were defined according to the Paxinos and Watson stereotaxic atlas of the rat brain (6th edition, 2007). The total labeling was measured by taking the mean of two optical densities on the same slice and on two successive slices. The mean non-specific labeling (measured on a region without $\mathrm{TH}$ or $\mathrm{TrpH}$ labeling) was subtracted of the total labeling. The measures were carried out on the olfactory tubercle $(\mathrm{Tu})$, a structure by which central neuromodulatory inputs enter the $\mathrm{OB}$.

Histochemical measurement of acetylcholinesterase activity Slides were incubated for $12 \mathrm{~h}$ in $180 \mathrm{~mL}$ of stock solution (see below) to which had been added $208 \mathrm{mg}$ of $\mathrm{S}$-acetylthiocholine iodide and $5.4 \mathrm{mg}$ ethopropazine. The slides were rinsed with deionized water and developed for $10 \mathrm{~min}$ in $1 \%$ sodium sulfide in phosphate buffer $0.1 \mathrm{M}$ at $\mathrm{pH} 7.5$. They were then rinsed three times for $5 \mathrm{~min}$ each with deionized water and immersed in $4 \%$ paraformaldehyde in phosphate buffer $0.1 \mathrm{M}$ for 30 $\mathrm{min}$, and then rinsed with distilled water (3 times; $5 \mathrm{~min}$ each). Subsequently, slides were dehydrated in series of ethanol baths $(50,70,96,100 \%)$ for $3 \mathrm{~min}$, and cleared with toluene twice for $5 \mathrm{~min}$. Slides were then coverslipped with Eukitt mounting medium (catalogue \#03989; Sigma, St. Louis, MO). The stock solution was a $50 \mathrm{mM}$ sodium acetate buffer at $\mathrm{pH} 5.0$ which was made $4.0 \mathrm{mM}$ with respect to copper sulphate and $16 \mathrm{mM}$ with respect to glycine. This was done by adding $6.8 \mathrm{~g}$ of sodium acetate, $1.0 \mathrm{~g}$ of copper sulphate crystals, and 1.2 $\mathrm{g}$ of glycine to $1.0 \mathrm{~L}$ of water and lowering the $\mathrm{pH}$ to 5.0 with $\mathrm{HCl}$.

Standards for specific acetylcholinesterase activity were prepared from whole brain homogenates of adult rabbits. Enzyme activity of brain homogenates was biochemically measured by spectrophotometry according to the protocol described by Ellman et al. and modified by Dumont et al. $[99,100]$. Briefly, brain homogenate $(\mathrm{pH}=8)$ was diluted with 5-5'-dithiobis-2-nitrobenzoate acid (DTNB, $0.01 \mathrm{M}$ ) and acetylthiocholine iodide $(75 \mathrm{mM})$. The thio-choline, formed during hydrolysis of acetylthiocholine, rapidly reacts with DTNB to release a colored 5-thio-2-nitrobenzoate anion with maximum absorption at $412 \mathrm{~nm}$. The specific enzymatic activity of acetylcholinesterase was calculated from the linear slope of the curve obtained and was $8.41 \mu \mathrm{mol} / \mathrm{min} / \mathrm{g}$ of tissue. Brain homogenate sections of variable thickness were used to cover the entire range of activity measured in the different brain structures. Under our experimental conditions, the staining intensity was highly correlated to the thickness of the standard sections (linear function with $r=0.997)$. Analysis of acetylcholinesterase stained sections was carried out with a BIOCOM 
computer-assisted image analysis system (Les Ulis, France), in which optical density readings were converted by means of standards into enzymatic activity values expressed in $\mu \mathrm{mol} / \mathrm{min} / \mathrm{g}$ of tissue. Anatomical structures were defined according to the Paxinos and Watson stereotaxic atlas of rat brain (6th edition, 2007). At least 3 optical density readings were taken of labeled regions to obtain a homogeneous evaluation.

\section{Olfactory-guided behavior}

The olfactory sensitivity of exposed or control pups was tested at PND2. 117 pups $(N=62$ control; $N=55$ exposed) born to 15 dams ( $N=8$ controls, $N=7$ exposed) were examined for their odor-guided behavior in response to the presentation of 2MB2 (catalogue \#136816; Sigma-Aldrich, Saint-Quentin Fallavier, France) as previously described $[90,91]$. To standardize the feeding status of newborn animals, the access of the mother to the nest was blocked at $5 \mathrm{pm}$ the day before the experiment and pups were individually tested at $8 \mathrm{am}$. The test consisted on taking each pup in a gloved hand with nest material, with its head left free to move. When the pup reached a state of relative immobility, the extremity of a glass-stick (length $\times$ diameter: $15 \times 0.3 \mathrm{~cm}$ ) carrying the 2MB2 stimulus (final concentration of $5.10^{-8} \mathrm{~g} / \mathrm{ml}$ in water, freshly prepared each day) was positioned $0.5 \mathrm{~cm}$ in front of its muzzle without contact with its skin or hair. The stimulus was presented for 10s and individual scores (yes or no) were recorded. Pups were considered to positively respond when they displayed searching movements, consisting of vigorous horizontal and vertical scanning of the head, after maximal stretching of the neck toward the stimulus. Results were expressed as the percentage of pups displaying searching and oral grasping responses when exposed to the molecule (i.e., positive responses). The final concentration used here has been reported to induce $60 \%$ of positive responses in control animals [90].

Thereafter, pups were immediately put back in the nest. The whole litter was tested in less than 15 min and the mother was allowed access to the nest at the end of the experiment. The glass-sticks were rinsed twice with pure ethanol and distilled water, and then dried between each pup.

\section{Statistical analysis}

For each variable measured in the present study, a Levene test for homogeneity of variances was performed. Thus, given that homogeneity of variance was assumed for most of the variables, a general linear model (GLM) was used for statistical analysis, adjusting the litter as a confounding variable. A Pearson chi-square procedure was used to analyze the percentage of animals that responded to the mammary pheromone $2 \mathrm{MB} 2$, without considering the litter or the sex, which was not checked at this step. Significance was set at $p<0.05$, tendency at $p<0.1$. All statistical analyses were carried out using SPSS 16.0 software (SPSS Inc., Chicago, IL, USA).

\section{Abbreviations \\ 2MB2: 2-Methyl-3-butyn-2-ol; 5-HIAA: 5-Hydroxyindoleacetic acid; 5- HT: Serotonin; AChE: Acetylcholinesterase; AD: Alzheimer's disease; CNS: Central nervous system; DA: Dopamine; DE: Diesel exhaust; DEP: Diesel exhaust particles; DOPAC: 3,4-Dihydroxyphenylacetic acid; F1: First generation; GD: Gestational day; GLM: General linear model; Gr: Granule cells; HVA: Homovanillic acid; K: Kynurenine; MHPG: 3-Methoxy-4- \\ hydroxyphenylglycol; NA: Noradrenaline; NP: Nanoparticles; OB: Olfactory bulb; OEC: Olfactory ensheating cells; OM: Olfactory mucosa; OSN: Olfactory sensory neurons; PD: Parkinson's disease; PG: Periglomerular cells; PM: Particulate matter; PND: Postnatal day; ROI: Selected area; TEM: Transmission Electron Microscopy; TH,: Tyrosine Hydroxylase; TRP: Tryptophan; TrpH: Tryptophan Hydroxylase; UFPM: Ultrafine particle matter}

\section{Acknowledgements}

We thank the UCEA (Unité Commune d'Expérimentation Animale) for housing the rabbits and participating to the experiments. This work has benefited from the facilities and expertise of the INRA MIMA2 platform (http://www6.jouy.inra.fr/mima2) for transmission electron microscopy, with a special thank to C. Longin. We thank Professor S.N. Thornton for reviewing and correction of the paper. We also thank John Boere and Paul Fokkens from the RIVM for DE exposure, which was performed with the mobile Ambient Particle Concentrator Exposure Laboratory.

\section{Funding}

The production of exposed and control animals was supported by ANR grant ANR-13-CESA-0011-EPAPP (P. Chavatte-Palmer) and by ERC consolidator grant N³11765-E-DOHaD (PI, Rémy Slama). Scientific exploration was financed by the French National Research Program for Environmental and Occupational Health of Anses (PNREST Anses, 2014/1/ 190) supervised by Henri Schroeder. The same program subcontracted to ADEME financially supported Estefanía Bernal-Melendez Ph.D.

\section{Availability of data and materials}

All data generated or analyzed during this study are included in this article (and its supplementary information files). The datasets analyzed during the current study are available from the corresponding author on request.

\section{Authors' contributions}

$C B, F C, A C T, M C L, P C P, D R R$ and $H S$ contributed to the idea and design of the study. JA, CB, DD, MCL and MAP performed the dissection of olfactory and brain tissues after sexing of the fetuses and recovery of heads by JA, PCP, ACT and DRR. EBM performed electronic microscopy. JA supervised the interpretation of TEM images. JC performed the bulbar monoaminergic neurochemical analysis by HPLC. EBM, PB, DD and BO performed the immunohistochemistry experiments. $C B$ and $M C L$ were responsible for the supervision of behavioral characterization of pups at PND2, which was technically conducted with the help of DD and MAP. EBM and HS performed the statistical analyses. CB and EBM wrote the draft manuscript, which was critically read and approved by all authors.

\section{Ethics approval}

Animals were treated according to the ethical standards defined by the National Institute for Agronomic Research (INRA) for animal health and care with strict compliance with the EEC recommendations (no. 86/609) and the 2010/63/EU directive on the protection of animals used for scientific purposes. The local ethical committee ( $\mathrm{N}^{\circ} 45$ in the French National register) approved the experimentation under $N^{\circ} 12 / 102$.

\section{Consent for publication}

Not applicable.

Competing interests

The authors declare that they have no competing interests. 


\section{Publisher's Note}

Springer Nature remains neutral with regard to jurisdictional claims in published maps and institutional affiliations.

\begin{abstract}
Author details
'NeuroBiologie de I'Olfaction, INRA, Université Paris-Saclay, 78350 Jouy-en-Josas, France. ${ }^{2}$ CALBINOTOX, Université de Lorraine, EA7488 Vandoeuvre-lès-Nancy, France. ${ }^{3}$ Service de Biochimie et Biologie Moléculaire, Hôpital Lariboisière, Paris, France. ${ }^{4}$ UMR BDR, INRA, ENVA, Université Paris Saclay, 78350 Jouy-en-Josas, France. ${ }^{5}$ Center for Sustainability, Environment and Health, National Institute for Public Health and the Environment, Bilthoven, Netherlands. ${ }^{6}$ Institute of Risk Assessment Sciences, Utrecht University, Utrecht, Netherlands.
\end{abstract}

\section{Received: 24 July 2018 Accepted: 20 December 2018} Published online: 17 January 2019

\section{References}

1. Ostro B, Broadwin R, Green S, Feng WY, Lipsett M. Fine particulate air pollution and mortality in nine California counties: results from CALFINE. Environ Health Perspect. 2006;1 14(1):29-33. https://doi.org/10.1289/ehp.8335.

2. Falcon-Rodriguez Cl, Osornio-Vargas AR, Sada-Ovalle I, Segura-Medina P. Aeroparticles, composition, and lung diseases. Front Immunol. 2016;7(JAN): 1-9. https://doi.org/10.3389/fimmu.2016.00003.

3. Xing YF, XU YH, Shi MH, Lian YX. The impact of PM2.5 on the human respiratory system. J Thorac Dis. 2016;8(1):E69-74. https://doi.org/10.3978/j. issn.2072-1439.2016.01.19

4. Donaldson K, Tran L, Jimenez LA, et al. Combustion-derived nanoparticles: a review of their toxicology following inhalation exposure. Part Fibre Toxicol. 2005;2:1-14. https://doi.org/10.1186/1743-8977-2-10.

5. Costa LG, Cole TB, Coburn J, Chang YC, Dao K, Roque P. Neurotoxicants are in the air: convergence of human, animal, and in vitro studies on the effects of air pollution on the brain. Biomed Res Int. 2014;2014. https://doi.org/10. 1155/2014/736385

6. Calderón-Garcidueñas. Safety Evaluation - Environmental Air Pollution and Brain Damage. 2002;30(3):373-89.

7. Hartz AMS, Bauer B, Block ML, Hong J-S, Miller DS. Diesel exhaust particles induce oxidative stress, proinflammatory signaling, and P-glycoprotein upregulation at the blood-brain barrier. FASEB J. 2008;22(8):2723-33. https:// doi.org/10.1096/fj.08-106997.

8. Block ML, Calderón-garcidueñas L. Air pollution: mechanisms of neuroinflammation and CNS disease. NIH Public Access. 2010;32(9):506-16. https://doi.org/10.1016/j.tins.2009.05.009.

9. Genc S, Zadeoglulari Z, Fuss SH, Genc K. The adverse effects of air pollution on the nervous system. J Toxicol. 2012;2012. https://doi.org/10.1155/2012/ 782462.

10. Block ML, Elder A, Auten RL, et al. The outdoor air pollution and brain health workshop. NIH Public Access. 2013;33(5):972-84. https://doi.org/10. 1016/j.neuro.2012.08.014

11. Cruts $B$, van Etten $L$, Tornqvist $H$, et al. Exposure to diesel exhaust induces changes in EEG in human volunteers. Part Fibre Toxicol. 2008;5(1):4. https:// doi.org/10.1186/1743-8977-5-4.

12. Ghio AJ, Smith CB, Madden MC. Diesel exhaust particles and airway inflammation. Curr Opin Pulm Med. 2012;18(2):144-50. https://doi.org/10. 1097/MCP.0b013e32834f0e2a.

13. Calderón-Garcidueñas L, Mora-Tiscareño A, Ontiveros E, et al. Air pollution, cognitive deficits and brain abnormalities: a pilot study with children and dogs. Brain Cogn. 2008;68(2):117-27. https://doi.org/10.1016/.bandc.2008.04.008

14. Fonken LK, XU X, Weil ZM, et al. Air pollution impairs cognition, provokes depressive-like behaviors and alters hippocampal cytokine expression and morphology. Mol Psychiatry. 2011;16(10):987-95. https://doi.org/10.1038/mp 2011.76.

15. Calderón-Garcidueñas L, Franco-Lira M, Henríquez-Roldán C, et al. Urban air pollution: influences on olfactory function and pathology in exposed children and young adults. Exp Toxicol Pathol. 2010;62(1):91-102. https:// doi.org/10.1016/j.etp.2009.02.117.

16. Power MC, Weisskopf MG, Alexeeff SE, Coull BA, Avron S, Schwartz J. Trafficrelated air pollution and cognitive function in a cohort of older men. Environ Health Perspect. 2011;119(5):682-7. https://doi.org/10.1289/ehp. 1002767.
17. Ranft U, Schikowski T, Sugiri D, Krutmann J, Krämer U. Long-term exposure to traffic-related particulate matter impairs cognitive function in the elderly. Environ Res. 2009;109(8):1004-11. https://doi.org/10.1016/j.envres.2009.08. 003.

18. Calderón-Garcidueñas $L$, Reed W, Maronpot RR, et al. Brain inflammation and Alzheimer's-like pathology in individuals exposed to severe air pollution. Toxicol Pathol. 2004;32(6):650-8. https://doi.org/10.1080/ 01926230490520232

19. Heusinkveld HJ, Wahle T, Campbell A, et al. Neurodegenerative and neurological disorders by small inhaled particles. Neurotoxicology. 2016;56: 94-106. https://doi.org/10.1016/j.neuro.2016.07.007.

20. Moulton PV, Yang W. Air pollution, oxidative stress, and alzheimer's disease. J Environ Public Health. 2012;2012(x). https://doi.org/10.1155/2012/472751

21. Calderón-Garcidueñas L, Franco-Lira M, Mora-Tiscareño A, Medina-Cortina H, Torres-Jardón R, Kavanaugh M. Early alzheimer's and parkinson's disease pathology in urban children: friend versus foe responses - it is time to face the evidence. Biomed Res Int. 2013;2013. https://doi.org/10.1155/2013/161687.

22. Calderon-Garciduenas $L$, Torres-Jardon R. The impact of Air pollutants on the brain. JAMA Psychiatry. 2015;59812:5-6. https://doi.org/10.1001/ jamapsychiatry.2015.57.2.

23. Grandjean P, Barouki R, Bellinger DC, et al. Life-long implications of developmental exposure to environmental stressors: new perspectives. Endocrinology. 2015;156(10):3408-15. https://doi.org/10.1210/EN.2015-1350.

24. Guxens M, Aguilera I, Ballester F, et al. Prenatal exposure to residential air pollution and infant mental development: modulation by antioxidants and detoxification factors. Environ Health Perspect. 2012;120(1):144-9. https:// doi.org/10.1289/ehp.1103469.

25. Guxens M, Garcia-Esteban R, Giorgis-Allemand L, et al. Air pollution during pregnancy and childhood cognitive and psychomotor development: six european birth cohorts. Epidemiology. 2014;25(5):636-47. https://doi.org/10. 1097/EDE.0000000000000133.

26. Freire $C$, Ramos R, Puertas $R$, et al. Association of traffic-related air pollution with cognitive development in children. J Epidemiol Community Heal. 2010; 64(3):223-8. https://doi.org/10.1136/jech.2008.084574.

27. Becerra TA, Wilhelm M, Olsen J, Cockburn M, Ritz BR. Ambient air pollution and autism in Los Angeles county, California. Environ Health. 2013;121(3): 380-6. https://doi.org/10.1289/ehp.1205827.

28. Calderón-Garcidueñas L, Leray E, Heydarpour P, Torres-Jardón R, Reis J. Air pollution, a rising environmental risk factor for cognition, neuroinflammation and neurodegeneration: the clinical impact on children and beyond. Rev Neurol (Paris). 2016;172(1):69-80. https://doi.org/10.1016/j. neurol.2015.10.008.

29. Harris MH, Gold DR, Rifas-Shiman SL, et al. Prenatal and childhood trafficrelated air pollution exposure and childhood executive function and behavior. Neurotoxicol Teratol. 2016. https://doi.org/10.1016/j.ntt.2016.06.008.

30. Lanphear BP. The impact of toxins on the developing brain. Annu Rev Public Health. 2015;36(1):211-30. https://doi.org/10.1146/annurev-publhealth-031912114413.

31. Newman NC, Ryan P, LeMasters G, et al. Traffic-related Air Pollution exposure in the first year of life and behavioral scores at 7 years of age. Environ Health Perspect. 2013;121(6):731-6. https://doi.org/10.1289/ehp. 1205555.

32. Siddique $\mathrm{S}$, Banerjee $\mathrm{M}$, Ray MR, Lahiri T. Attention-deficit hyperactivity disorder in children chronically exposed to high level of vehicular pollution. Eur J Pediatr. 2011;170(7):923-9. https://doi.org/10.1007/s00431-010-1379-0.

33. Allen JL, Liu X, Pelkowski S, et al. Early postnatal exposure to ultrafine particulate matter Air Pollution: persistent Ventriculomegaly, neurochemical disruption, and glial activation preferentially in male mice. Environ Health Perspect. 2014;122(May):939-45. https://doi.org/10.1289/ehp.1307984.

34. Bolton JL, Huff NC, Smith SH, et al. Maternal stress and effects of prenatal air pollution on offspring mental health outcomes in mice. Environ Health Perspect. 2013;121(9):1075-82. https://doi.org/10.1289/ehp.1306560.

35. Ema M, Naya M, Horimoto M, Kato H. Developmental toxicity of diesel exhaust: a review of studies in experimental animals. Reprod Toxicol. 2013; 42:1-17. https://doi.org/10.1016/j.reprotox.2013.06.074.

36. Hougaard KS, Campagnolo L, Chavatte-Palmer P, et al. A perspective on the developmental toxicity of inhaled nanoparticles. Reprod Toxicol. 2015;56: 118-40. https://doi.org/10.1016/.j.reprotox.2015.05.015.

37. Sugamata M, Ihara T, Sugamata M, Takeda K. Maternal exposure to diesel exhaust leads to pathological similarity to autism in newborns. J Heal Sci. 2006;52(4):486-8. https://doi.org/10.1248/jhs.52.486. 
38. Wong CT, Wais J, Crawford DA. Prenatal exposure to common environmenta factors affects brain lipids and increases risk of developing autism Spectrum disorders. Eur J Neurosci. 2015. https://doi.org/10.1111/ejn.13028.

39. Sugamata M, Ihara T, Takano H, Oshio S, Takeda K. Maternal diesel exhaust exposure damages newborn murine brains. J Heal Sci. 2006;52(1):82-4. https://doi.org/10.1248/jhs.52.82.

40. Klocke C, Allen JL, Sobolewski M, et al. Neuropathological consequences of gestational exposure to concentrated ambient fine and ultrafine particles in the mouse. Toxicol Sci. 2017;156(2):492-508. https://doi.org/10.1093/toxsci/ kfx010.

41. Yokota S, Moriya N, Iwata M, Umezawa M, Oshio S, Takeda KK. Exposure to diesel exhaust during fetal period affects behavior and neurotransmitters in male offspring mice. J Toxicol Sci. 2013;38(1):13-23. https://doi.org/10.2131/ jts.38.13.

42. Yokota S, Mizuo K, Moriya N, Oshio S, Sugawara I, Takeda K. Effect of prenatal exposure to diesel exhaust on dopaminergic system in mice. Neurosci Lett. 2009;449(1):38-41. https://doi.org/10.1016/j.neulet.2008.09.085.

43. Yokota S, Oshio S, Takeda K. In utero exposure to diesel exhaust particles induces anxiogenic effects on male offspring via chronic activation of serotonergic neuron in dorsal raphe. Nucleus. 2016;41(5):583-93.

44. Suzuki T, Oshio S, Iwata $\mathrm{M}$, et al. In utero exposure to a low concentration of diesel exhaust affects spontaneous locomotor activity and monoaminergic system in male mice. Part Fibre Toxicol. 2010;7:7. https://doi.org/10.1186/17438977-7-7.

45. Yokota S, Sato A, Umezawa M, Oshio S, Takeda K. In utero exposure of mice to diesel exhaust particles affects spatial learning and memory with reduced $\mathrm{N}$-methyl-d-aspartate receptor expression in the hippocampus of male offspring. Neurotoxicology. 2015;50:108-15. https://doi.org/10.1016/j.neuro. 2015.08.009.

46. Hougaard KS, K a J, Nordly P, et al. Effects of prenatal exposure to diesel exhaust particles on postnatal development, behavior, genotoxicity and inflammation in mice. Part Fibre Toxicol. 2008;5:3. https://doi.org/10.1186/ 1743-8977-5-3.

47. Bolton JL, Marinero S, Hassanzadeh T, et al. Gestational exposure to air pollution alters cortical volume, microglial morphology, and microglianeuron interactions in a sex-specific manner. Front Synaptic Neurosci. 2017; 9(MAY):1-16. https://doi.org/10.3389/fnsyn.2017.00010.

48. Bolton JL, Smith SH, Huff NC, et al. Prenatal air pollution exposure induces neuroinflammation and predisposes offspring to weight gain in adulthood in a sex-specific manner. FASEB J. 2012;26(11):4743-54. https://doi.org/10. 1096/fj.12-210989.

49. Doty RL. Neurobiology of disease olfaction in Parkinson 's disease and related disorders. Neurobiol Dis. 2012;46(3):527-52. https://doi.org/10.1016/j. nbd.2011.10.026.

50. Rey NL, Wesson DW, Brundin P. The olfactory bulb as the entry site for prion-like propagation in neurodegenerative diseases. Neurobiol Dis. 2018; 109:226-48. https://doi.org/10.1016/j.nbd.2016.12.013.

51. Calderón-Garcidueñas L, Valencia-Salazar G, Rodríguez-Alcaraz A, et al. Ultrastructural nasal pathology in children chronically and sequentially exposed to air pollutants. Am J Respir Cell Mol Biol. 2001;24(2):132-8. https://doi.org/10.1165/ajrcmb.24.2.4157.

52. Levesque S, Surace MJ, McDonald J, Block ML. Air pollution and the brain: subchronic diesel exhaust exposure causes neuroinflammation and elevates early markers of neurodegenerative disease. J Neuroinflammation. 2011;8:110. https://doi.org/10.1186/1742-2094-8-105.

53. Peters A, Veronesi B, Calderón-Garcidueñas L, et al. Translocation and potential neurological effects of fine and ultrafine particles a critical update. Part Fibre Toxicol. 2006;3(13). https://doi.org/10.1186/1743-8977-3-13.

54. Calderón-Garcidueñas L, Solt AC, Henríquez-Roldán C, et al. Long-term air pollution exposure is associated with neuroinflammation, an altered innate immune response, disruption of the blood-brain barrier, ultrafine particulate deposition, and accumulation of amyloid beta-42 and alpha-synuclein in children and youn. Toxicol Pathol. 2008;36(2):289-310. https://doi.org/10. 1177/0192623307313011.

55. Doty RL. Olfactory dysfunction in Parkinson disease. Nat Rev Neurol. 2012; 8(6):329-39. https://doi.org/10.1038/nrneurol.2012.80.

56. Attems J, Lintner F, Jellinger KA. Olfactory involvement in aging and Alzheimer 's disease: An autopsy study. 2005;7:149-57. https://doi.org/10. 3233/jad-2005-7208.

57. Levesque S, Taetzsch T, Lull ME, et al. Diesel exhaust activates and primes microglia: Air pollution, neuroinflammation, and regulation of dopaminergic neurotoxicity. Environ Health Perspect. 2011;119(8):1149-55. https://doi.org/ 10.1289/ehp.1002986.

58. Huisman E, Hoogland P V. A 100\% Increase of Dopaminergic Cells in the Olfactory Bulb May Explain Hyposmia in Parkinson 's Disease. 2004;19(6): 145-148. https://doi.org/10.1002/mds.10713.

59. Huisman E, Uylings HBM, Hoogland P V. Gender-Related Changes in Increase of Dopaminergic Neurons in the Olfactory Bulb of Parkinson ' $s$ Disease Patients. 2008;23(10):1407-1413. https://doi.org/10.1002/mds.22009.

60. Mundiñano IC, Caballero MC, Ordóñez C, et al. Increased dopaminergic cells and protein aggregates in the olfactory bulb of patients with neurodegenerative disorders. Acta Neuropathol. 2011;122(1):61-74. https:/doi.org/10.1007/s00401011-0830-2.

61. Kovacs I. Cholinergic structures and neuropathologic alterations in the olfactory bulb of Alzheimer' s disease brain samples. 1998:167-170. https:// doi.org/10.1016/s0006-8993(98)00097-3.

62. Valentino SA, Tarrade A, Aioun J, et al. Maternal exposure to diluted diesel engine exhaust alters placental function and induces intergenerational effects in rabbits. Part Fibre Toxicol. 2016:1-14. https://doi.org/10.1186/ s12989-016-0151-7.

63. Fischer B, Chavatte-Palmer P, Viebahn C, Santos AN, Duranthon V. Rabbit as a reproductive model for human health. Reproduction. 2012;144(1):1-10. https://doi.org/10.1530/REP-12-0091.

64. Aïoun J, Tarrade A, Valentino S, et al. Transplacental tranfer of nanoparticles inhaled due to maternal exposure to filtered diesel engine exhaust during pregnancy in a rabbit model. Placenta. 2016. https://doi.org/10.1021/jp803475g.

65. Migliore M, Cavarretta F, Marasco A, Tulumello E, Hines ML, Shepherd GM. Synaptic clusters function as odor operators in the olfactory bulb. Proc Natl Acad Sci. 2015;112(27):8499-504. https://doi.org/10.1073/pnas.1502513112.

66. Willhite DC, Nguyen KT, Masurkar AV, Greer CA, Shepherd GM, Chen WR. Viral tracing identifies distributed columnar organization in the olfactory bulb. Proc Natl Acad Sci. 2006;103(33):12592-7. https://doi.org/10.1073/pnas. 0602032103.

67. Schaal B, Coureaud G, Langlois D, Giniès C, Sémon E, Perrier G. Chemical and behavioural characterization of the rabbit mammary pheromone. Nature. 2003;424(6944):68-72. https://doi.org/10.1038/nature01739.

68. Blunk T, Hochstrasser DF, Sanchez JC, Muller BW, Muller RH. Colloidal carriers for intravenous drug targeting: plasma protein adsorption patterns on surface-modified latex particles evaluated by two- dimensiona polyacrylamide gel electrophoresis. Electrophoresis. 1993;14(1):1382-87. https://doi.org/10.1002/elps.11501401214

69. Gerlofs-Nijland ME, van Berlo D, Cassee FR, Schins RPF, Wang K, Campbell A. Effect of prolonged exposure to diesel engine exhaust on proinflammatory markers in different regions of the rat brain. Part Fibre Toxicol. 2010;7(1):12. https://doi.org/10.1186/1743-8977-7-12.

70. Gessner A, Waicz R, Lieske A, Paulke BR, Mäder K, Müller RH. Nanoparticles with decreasing surface hydrophobicities: influence on plasma protein adsorption. Int J Pharm. 2000;196(2):245-9. https://doi.org/10.1016/S03785173(99)00432-9.

71. Lück M, Paulke B-R, Schröder W, Blunk T, Müller RH. Analysis of plasma protein adsorption on polymeric nanoparticles with different surface characteristics. J Biomed Mater Res. 1998;39(3):478-85 https://doi.org/10. 1002/(SICI)1097-4636(19980305)39:3\%3C478::AID-JBM19\%3E3.0.CO;2-6.

72. Maher BA, Ahmed IAM, Karloukovski V, et al. Magnetite pollution nanoparticles in the human brain. Proc Natl Acad Sci. 2016;113(39):10797801. https://doi.org/10.1073/pnas.1605941113.

73. Miller MR, Raftis JB, Langrish JP, et al. Inhaled nanoparticles accumulate at sites of vascular disease. ACS Nano. 2017;11(5):4542-52. https://doi.org/10. 1021/acsnano.6b08551.

74. Ibald-Mulli a, Wichmann HE, Kreyling W, Peters a. Epidemiological evidence on health effects of ultrafine particles. J Aerosol Med. 2002;15(2):189-201. https://doi.org/10.1183/09031936.00198013.

75. Nel A. Air Pollution - Related illness : Effects of Particles. Science (80- ). 2005 308(5723):804-6. https://doi.org/10.1126/science.1108752.

76. World Health Organization. Review of evidence on health aspects of air pollution - REVIHAAP Project. 2013:309. http://www.euro.who.int/en/healthtopics/environment-and-health/air-quality/publications/2013/review-ofevidence-on-health-aspects-of-air-pollution-revihaap-project-final-technicalreport.

77. Levy RJ. Carbon monoxide pollution and neurodevelopment: a public health concern. Neurotoxicol Teratol. 2015. https://doi.org/10.1016/j.ntt.2015. 03.001 . 
78. Suades-González E, Gascon M, Guxens M, Sunyer J. Air Pollution and neuropsychological development: a review of the latest evidence. Endocrinology. 2015;(August):en20151403. https://doi.org/10.1210/en.2015-1403

79. Schroeder $\mathrm{H}$. Developmental brain and behavior toxicity of Air pollutants: a focus on the effects of polycyclic aromatic hydrocarbons (PAHs). Crit Rev Environ Sci Technol. 2011;41(22):2026-47. https://doi.org/10.1080/10643389. 2010.495644.

80. Elder A, Gelein R, Silva V, et al. Translocation of Inhaled Ultrafine Manganese Oxide Particles to the Central Nervous System. 2006. https://doi.org/10. 1289/ehp.9030.

81. Nemmar A, Vanbilloen H, Hoylaerts MF, PHM H, Verbruggen A, Nemery B. Passage of Intratracheally instilled ultrafine particles from the lung into the systemic circulation in hamster. About Am J Respir Crit Care Med. 2001; 164(9):1665-8. https://doi.org/10.1164/rccm2101036.

82. Hervé F, Ghinea N, Scherrmann J-M. CNS delivery via adsorptive transcytosis. AAPS J. 2008;10(3):455-72. https://doi.org/10.1208/s12248-008-9055-2.

83. Woodward N, Finch CE, Morgan TE. HHS Public Access. 2016;2(2):353-73. https://doi.org/10.3934/environsci.2015.2.353.Traffic-related.

84. Machado JDB, Chatkin JM, Zimmer AR, Goulart APS, Thiesen FV. Cotinine and polycyclic aromatic hydrocarbons levels in the amniotic fluid and fetal cord at birth and in the urine from pregnant smokers. PLoS One. 2014;9(12): 1-12. https://doi.org/10.1371/journal.pone.0116293.

85. González-Maciel A, Reynoso-Robles R, Torres-Jardón R, Mukherjee PS, Calderón-Garcidueñas L. Combustion-derived nanoparticles in key brain target cells and organelles in young urbanites: culprit hidden in plain sight in Alzheimer's disease development. J Alzheimers Dis. 2017;59(1):189-208. https://doi.org/10.3233/JAD-170012.

86. Yokota S, Oshio S, Moriya N, Takeda K. Social isolation-induced territorial aggression in male offspring is enhanced by exposure to diesel exhaust during pregnancy. PLoS One. 2016;11(2):1-15. https://doi.org/10.1371/ journal.pone.0149737.

87. Bolton $\mathrm{J}$, Auten RL, Bilbo SD. Prenatal air pollution exposure induces sexually dimorphic fetal programming of metabolic and neuroinflammatory outcomes in adult offspring. Brain Behav Immun. 2014;37:30-44. https://doi. org/10.1016/j.bbi.2013.10.029.

88. Allen JL, Liu X, Weston D, et al. Developmental exposure to concentrated ambient ultrafine particulate matter air pollution in mice results in persistent and sex-dependent behavioral neurotoxicity and glial activation Toxicol Sci. 2014;140(1):160-78. https://doi.org/10.1093/toxsci/kfu059.

89. Calderón-Garcidueñas L, Gónzalez-Maciel A, Reynoso-Robles R, et al. Hallmarks of Alzheimer disease are evolving relentlessly in metropolitan Mexico City infants, children and young adults. APOE4 carriers have higher suicide risk and higher odds of reaching NFT stage $V$ at $\leq 40$ years of age. Environ Res. 2018;164(December 2017):475-87. https://doi.org/10.1016/j. envres.2018.03.023.

90. Coureaud G, Langlois D, Sicard G, Schaal B. Newborn rabbit responsiveness to the mammary pheromone is concentration-dependent. Chem Senses. 2004;29(4):341-50. https://doi.org/10.1093/chemse/bjh037.

91. Coureaud G, Charra R, Datiche F, et al. A pheromone to behave, a pheromone to learn: the rabbit mammary pheromone. J Comp Physiol A Neuroethol Sensory, Neural. Behav Physiol. 2010;196(10):779-90. https://doi. org/10.1007/s00359-010-0548-y.

92. Charra R, Datiche F, Gigot V, Schaal B, Coureaud G. Pheromone-induced odor learning modifies Fos expression in the newborn rabbit brain. Behav Brain Res. 2013;237(1):129-40. https://doi.org/10.1016/j.bbr.2012.09.017.

93. Mascagni P, Consonni D, Bregante G, Chiappino G, Toffoletto F. Olfactory function in workers exposed to moderate airborne cadmium levels. Neurotoxicology. 2003;24(4-5):717-24. https://doi.org/10.1016/S0161$813 \times(03) 00024-X$.

94. Dorman DC, Struve MF, Gross EA, Wong BA, Howroyd PC. Sub-chronic inhalation of high concentrations of manganese sulfate induces lower airway pathology in rhesus monkeys. Respir Res. 2005;6:1-10. https://doi. org/10.1186/1465-9921-6-121.

95. Landrigan PJ, Sonawane B, Butler RN, Trasande L, Callan R, Droller D. Early environmental origins of neurodegenerative disease in later life. Environ Health Perspect. 2005;113(9):1230-3. https://doi.org/10.1289/ehp.7571.

96. Freney EJ, Heal MR, Donovan RJ, et al. A single-particle characterization of a mobile versatile aerosol concentration enrichment system for exposure studies. Part Fibre Toxicol. 2006;3:1-11. https://doi.org/10.1186/1743-8977-3-8.

97. Gamache P, Ryan E, Svendsen C, Murayama K, Acworth IN. Simultaneous measurement of monoamines, metabolites and amino acids in brain tissue and microdialysis perfusates. J Chromatogr B Biomed Sci Appl. 1993;614(2): 213-20. https://doi.org/10.1016/0378-4347(93)80311-Q.

98. Kema IP, Schellings AMJ, Hoppenbrouwers CJM, Rutgers HM, de Vries EGE, Muskiet FAJ. High performance liquid chromatographic profiling of tryptophan and related indoles in body fluids and tissues of carcinoid patients. Clin Chim Acta. 1993;221(1-2):143-58. https://doi.org/10.1016/ 0009-8981(93)90029-4.

99. Ellman GL, Courtney KD, Andres V, Featherstone RM. A new and rapid colorimetric determination of acetylcholinesterase activity. Biochem Pharmacol. 1961;7(2):88-95. https://doi.org/10.1016/0006-2952(61)90145-9.

100. Dumont M, Lalonde R, Ghersi-Egea JF, Fukuchi K, Strazielle C. Regional acetylcholinesterase activity and its correlation with behavioral performances in 15-month old transgenic mice expressing the human C99 fragment of APP. J Neural Transm. 2006;113(9):1225-41. https://doi.org/10. 1007/s00702-005-0373-6.

\section{Ready to submit your research? Choose BMC and benefit from:}

- fast, convenient online submission

- thorough peer review by experienced researchers in your field

- rapid publication on acceptance

- support for research data, including large and complex data types

- gold Open Access which fosters wider collaboration and increased citations

- maximum visibility for your research: over $100 \mathrm{M}$ website views per year

At BMC, research is always in progress.

Learn more biomedcentral.com/submissions 